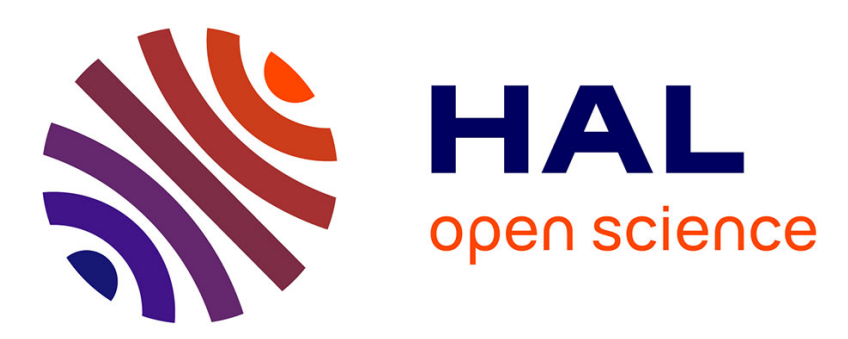

\title{
A Heuristic-Based Genetic Algorithm for Scheduling of Multiple Projects Subjected to Resource Constraints and Environmental Responsibility Commitments
}

Shadan Gholizadeh-Tayyar, Uche Okongwu, Jacques Lamothe

\section{- To cite this version:}

Shadan Gholizadeh-Tayyar, Uche Okongwu, Jacques Lamothe. A Heuristic-Based Genetic Algorithm for Scheduling of Multiple Projects Subjected to Resource Constraints and Environmental Responsibility Commitments. Process Integration and Optimization for Sustainability, 2021, 5 (3), pp.361-382. 10.1007/s41660-020-00150-7 . hal-03224259

\section{HAL Id: hal-03224259 \\ https://imt-mines-albi.hal.science/hal-03224259}

Submitted on 29 Jun 2021

HAL is a multi-disciplinary open access archive for the deposit and dissemination of scientific research documents, whether they are published or not. The documents may come from teaching and research institutions in France or abroad, or from public or private research centers.
L'archive ouverte pluridisciplinaire HAL, est destinée au dépôt et à la diffusion de documents scientifiques de niveau recherche, publiés ou non, émanant des établissements d'enseignement et de recherche français ou étrangers, des laboratoires publics ou privés. 


\title{
A Heuristic-based genetic algorithm for scheduling of multiple projects subjected to resource constraints and environmental responsibility commitments
}

\author{
S. Gholizadeh - Tayyar ${ }^{1}$, U. Okongwu ${ }^{2}$, J. Lamothe ${ }^{3}$ \\ ${ }^{1}$ Université de Cergy-Pontoise, Département gestion logistique et transport, 95 Rue Valère Collas, Argenteuil, France \\ ${ }^{2}$ Department of Information, Operations and Management Sciences, 20 Boulevard Lascrosses, Toulouse, France \\ ${ }^{3}$ Université Federale Toulouse Midi-Pyrenees, IMT Mines Albi, Industrial Engineering Department, Albi, France
}

\begin{abstract}
During the last decades, resource constrained project scheduling problems have been abundantly presented in extant literature. However, there are still some real-world challenges that have not been adequately considered. These challenges include environmental commitments and constraints related to the procurement of resources (as regards procurement commitment). This calls for the integration of the project planning and forward-reverse supply chain planning systems. To achieve this goal, this paper contributes to the existing literature by presenting a model that incorporates the two issues in the integrated planning system: 1) the procurement commitment objective is met through the just-in-time delivery of non-renewable resources to the project sites while considering the limited supply capacity of suppliers and 2) the environmental commitment is satisfied by collecting and recycling the waste generated at project sites. A mixed integer linear formulation of the problem is proposed. Since the model is NP-hard (Non-deterministic Polynomial time-hard), the paper develops a new heuristic-based genetic algorithm to solve the problem instances. The main parameters of the algorithm are tuned using the Taguchi method. The results show the efficiency of the algorithm in obtaining appropriate solutions in reasonable computational times. The integrated planning model that is proposed in this paper and its novel resolution method would help managers to make more responsive and efficient decisions.
\end{abstract}

Key words Resource constrained multi-project scheduling problem; Supply chain planning; Environmental responsibility; Combinatorial optimization; Genetic algorithm; Taguchi design.

\section{Introduction}

This section is organized in two parts. The first part gives an overview of the research background and highlights the main aspects of the problem studied. The second part presents the use case that inspired the contributions of the paper.

\subsection{Background of the research}


Resource Constrained Project Scheduling Problem (RCPSP) is one of the most important topics of study in operations research and management science. In RCPSPs, the objective of the problem is to schedule project activities and determine how limited resources should be allocated to them in order to optimally satisfy one or several predetermined criteria (Pritsker et al. 1969).

Lova and Tormos (2001) reported that up to $84 \%$ of the values of all projects are realized in a multiproject environment. This fact highlights the importance of Resource Constrained Multi Project Scheduling Problems (RCMPSP). In the scheduling of multi-projects, the efforts of decision makers are generally focused on the allocation of resources to projects. Investigating resource allocation issues in RCMPSPs, Herroelen (2005) stressed the necessity of developing appropriate approaches to deal with constrained resources in multi projects. According to Węglarz et al. (2011), two types of resources - renewable and non-renewable - are required to perform project activities. Renewable resources, such as labour and machinery, are released after the accomplishment of the activities to which they were assigned, such that they can immediately be reused by other eligible activities. Regarding the non-renewable resources, such as construction materials, they are depleted by usage and are therefore continuously supplied to the project sites during the execution phase.

In many building renovation and energy efficiency improvement projects, the required nonrenewable resources are often of high value and low demand. Therefore, the first key issue in this study deals with planning to deliver the right quantities of the high value non-renewable resources just-in-time in order to achieve operational objectives such as the minimization of the inventory levels and costs. In conventional project scheduling approaches, the scheduling of activities and the planning of non-renewable resources (materials) ordering are considered separately. In other words, a schedule is first determined and then the required materials are ordered accordingly. Aquilano and Smith (1980) argued that this policy leads to different drawbacks due to the fact that trade-offs between the decisions on activity scheduling and material ordering are neglected. Therefore, the authors proposed to integrate Project Scheduling Problems (PSPs) with Material Ordering (MO) models. Nevertheless, their integrated PSP-MO model considers only the lead-time for material acquisition and assumes that ready-to-use materials can be stored on the project sites. Regarding the high-value materials, there are some challenges. Indeed, the inventory levels of these resources on the project sites should be kept to a minimum so as to reduce the storage costs. One way to achieve this is by asking the suppliers/manufacturers of these materials to deliver them just-in-time to the project sites. Considering a situation where the required materials are supplied just-in-time throughout the supply chain network, it can be argued that the limited supply (transportation and/or production) capacity of the suppliers / manufacturers as well as the constraints related to just-in-time delivery can significantly impact not only the procurement (transportation and production) of the materials, but also the schedules of the activities. On the other hand, project planning constraints such as the due-dates and the execution time-windows of activities can impact the supply quantities of the non-renewable resources to the project sites. Therefore, the optimal decision may not be made 
without considering the impacts of the suppliers'/manufacturers' constraints on the scheduling of the projects and also the impact of the project scheduling constraints on the production and transportation planning of the non-renewable resources in the supply chain. For this reason, the model proposed in this paper aims to integrate an RCMPSP with the problem related to the planning of the supply of materials under limited transportation and production capacities of the manufacturers and/or suppliers. With reference to the definition of supply chain planning (SCP) given by de Kok and Fransoo (2003), we denote that our paper presents a new model that integrates RCMPSP and SCP problems.

The second key issue in this paper has to do with the execution of projects in an environmentalfriendly manner. The increasing concerns about the management of natural resources and the protection of the environment have led to considering sustainability factors as an inseparable part of decisional procedures (Robichaud Lauren Bradley and Anantatmula Vittal 2011; Tayyar et al. 2013; Bandyopadhyay et al. 2017; Torabzadeh Khorasani 2018; Rabbani et al. 2019; Jain et al. 2020). In this respect, the management of the wastes generated during the execution and closure of construction projects has become an important subject for both researchers and practitioners. Wang et al. (2018) reported that construction and demolition wastes form approximately $30 \%$ to $40 \%$ of all solid wastes generated worldwide. A systematic collection- recycling plan is therefore significantly needed.

With this in view, an important dimension to be added in modelling frameworks for PSPs is the determination of a plan to optimally collect the wastes from project worksites and transport them to appropriate recycling centres. In establishing such a plan, it will be inevitable to take into account the project scheduling constraints as well as the transportation and recycling capacity constraints.

To respond to the above-mentioned requirements, a new mathematical model, which is an extension of project scheduling problems, and a genetic algorithm-based resolution method are developed in our study.

Based on the above discussion, we observe that some issues encountered in many real-world cases are not adequately addressed in the literature of project scheduling problems. These issues include the constraints related to the procurement and delivery of non-renewable resources to project worksites as well as environmental commitments. The consideration of these issues leads to asking the following questions:

- What modelling framework can be used to optimally plan and schedule activities in multiple projects that are subjected to the just-in-time delivery of non-renewable resources by suppliers with limited supply capacity, while taking into consideration) the environmental concerns related to the collection and recycling of the wastes generated at the project worksites? 
- How can the model be presented mathematically through a mixed integer programming problem?

- What methods can be applied in order to solve the instances of the problem to optimality?

\subsection{The case used for the research}

Following a directive issued in 2009 by the French government, the country committed itself to combat climate change and reduce its greenhouse gas emissions by $75 \%$ by 2050 (Légifrance 2009). Given that the building sector generates $24 \%$ of the total emissions in the country, it is key to reaching the objectives of the climate change policy (Légifrance 2009). Consequently, the French agency for environment and energy management elaborated a project that aims to reduce the total energy consumption level of buildings in France. The objective of this project, named CRIBA (Construction et Rénovation Industrialisée Bois et Acier), is to reduce energy consumption from about $200 \mathrm{kWh} / \mathrm{m}^{2} /$ year to only $25 \mathrm{kWh} / \mathrm{m}^{2} /$ year in 500000 habitations. The solution to achieve this goal is to install insulated-prefabricated panels on the buildings' external facades, and to replace the existing heating and hot water systems with energy-saving ones.

The theoretical framework of this study responds to the requirements that project planners engage in scheduling of the renovation activities in different worksites of the CRIBA project. The main specificities of the implementation and accomplishment of the thermal renovation projects in the CRIBA context are:

- Just-in-time supply of the prefabricated isolation panels with the aim of reducing the inventory levels of high-value materials on the worksites while also protecting the panels from different hazards that can damage them;

- Regular collection and shipment of wastes from the worksites to appropriate recycling centres in order to meet environmental responsibility objectives;

- Limited transportation, production and recycling capacities of the supply chain actors, coupled with the due-dates and time windows that are imposed for the execution of renovation activities.

The remainder of the paper starts with a review of the literature and the formulation of our research objectives. Then, it continues with the description of the model before presenting the proposed solution method and the numerical results obtained from the application of the developed method. Finally, the paper ends by presenting a summary of the study, its limitations in practice and perspectives for future works.

\section{Literature review}

In section 1.1, we outlined three aspects of this paper that constitute its main contribution: 1) project scheduling with the integration of issues related to material (non-renewable resource) procurement; 
2) project scheduling considering environmental responsibility commitments, with specific attention to the collection, transportation and recycling of wastes generated on project sites; 3) resolution methods, with particular emphasis on metaheuristics and genetic algorithms. The review of the literature will be presented with respect to these three issues and will enable us to position the contribution of this paper.

\subsection{Project scheduling with material procurement issues}

After highlighting the shortcomings of separating project scheduling and material ordering problems, Aquilano and Smith (1980) proposed to integrate PSPs with MO models and built the schedule of the project activities by considering the impact of the lead-times of the acquisition of materials. Following this work, Smith-Daniels and Aquilano (1984) investigated a single project scheduling problem that considered the planning of both non-renewable and renewable resources. Smith-Daniels and Smith-Daniels (1987a) later worked on the integration of PSP and MO with respect to the maximization of the net present value of money. Smith-Daniels and Smith-Daniels (1987b) presented a model that considered the lead-times for material ordering and assumed a due-date for project closure. In a subsequent research, Dodin and Elimam (2001) extended the work of SmithDaniels and Smith-Daniels (1987b) by incorporating the variability in the duration of activities, with the aim to minimize the total cost of executing the project. Sheikh Sajadieh (2009) studied the impact of discounts on material acquisition costs. Assuming that unlimited quantities of the non-renewable resources can be kept on the project site, Nima et al. (2012) studied a single project scheduling problem with a given due-date for the completion of the project and also with predetermined time windows for the execution of the activities. To solve the model instances, they developed a hybrid algorithm that combined the genetic and simulated annealing algorithms. Niaki et al. (2015) extended the work of Nima et al. (2012) by incorporating order lead-times and also scheduling for the constrained renewable resources. Tabrizi and Ghaderi (2016) extended the model in (Sheikh Sajadieh 2009) by including the constraint of limited capacity for storing the materials. Further still, Tabrizi and Ghaderi (2016) investigated the execution cost for single project scheduling as well as the effect of uncertainty in activity durations. Following up their work in (Niaki et al., 2015), Zoraghi et al. (2017) investigated the combination of multi-mode project scheduling problem in resource investment and quantity discount model in material ordering. A project scheduling problem with the generalized precedence relations including finish to start, start to start, start to finish and finish to finish precedencies subjected to material ordering issues is studied in (Gholizadeh-Tayyar et al., 2018). The most recent paper in this context is presented by Habibi et al. (2019), where the authors studied an integrated project scheduling and material ordering problem and looked at the environmental and social merits of the potential suppliers of the project resources. 
This overview of the extant literature reveals a lack of studies on the philosophy of the delivery of materials to the project sites with special emphasis on the limited procurement capacity (production and transportation capacities) of the suppliers and just-in-time delivery of the non-renewable resources. Therefore, this paper aims to fill this gap by presenting an integrated framework for project scheduling and supply chain planning systems.

\subsection{Project scheduling with environmental responsibility commitments}

In the context of project management, environmental responsibility commitments can be studied from two perspectives of the execution process: forward (related to material ordering and delivery) or reverse (related to the collection and recycling of wastes generated during the execution of the project activities). Our paper focuses on the reverse perspective, that is, the management of generated wastes, which has in recent times been of particular interest to researchers (see (Shen and Tam, 2002; Gálvez-Martos et al. 2018)). Lachimpadi et al. (2012) provided a synthesis of principles and best practices to improve resource efficiency and environmental impact as regards the management of wastes in construction and demolition projects in Europe. Based on the information gathered from interviews, Udawatta et al. (2015) aimed to provide new solutions to efficiently manage and reduce waste generation in construction projects. Today, there is no existing solution that enables to reduce waste generation to zero. There is therefore the need to develop solutions for collecting and recycling these wastes. In the field of manufacturing supply chain management, a large body of research has been done on closed-loop logistics, where wastes are transported from customers to recycling centres (Kannan et al. 2010; Subramanian et al. 2012; Battini et al. 2017; Kim et al. 2018; Prakash et al. 2020). But, in the context of project scheduling problems, a lot of research is still required (to the best of our knowledge) to develop mathematical models that optimally plan waste management operations. This paper aims to consider in the project scheduling problem the optimal planning of the collection, transportation and recycling of the wastes generated on the project sites. It proposes a new Mixed Integer Linear Programming (MIP) model. To solve the instances of the model, the development of an efficient resolution method is needed.

\subsection{Resolution methods}

Constrained project scheduling problems are NP-hard problems (Blazewicz et al. 1983), and any generalization of classical problems is also NP-hard. For this reason, exact methods become computationally intractable when solving large-size instances. To tackle this difficulty, many researchers have studied and suggested the use of metaheuristics. In metaheuristics, the Serial Schedule Generation Scheme (SSGS), which is a stepwise process, schedules the eligible activities at the earliest precedence and resource-feasible start time (Kelley 1963). 
In PSPs, the genetic algorithm (GA) has been widely used in research. A review of 304 papers published (in SpringerLink, ScienceDirect, Taylor and Francis and IEEE) on resource constrained project scheduling problems between 2000 and 2020 revealed that 132 used the genetic algorithm. The wide use of the GA can be linked to its advantage of being a population-based search approach as well as to its strong ability to explore and exploit the solution space. Alcaraz and Maroto (2001) proposed a genetic algorithm where they generalize the activity list in SSGS method. The procedure defined by Toklu (2002) benefits from a penalty function that enables to repair probable infeasible off-springs. Gonçalves et al. (2008) studied a GA for the resource constrained multi-project scheduling problem. The initialization procedure of their GA relies on heuristics that produce parameterized schedules based on priorities, delay times and release dates. Browning and Yassine (2010) presented a review of the applications of different heuristics used for the resolution of multiproject scheduling problems. Wauters et al. (2016) discussed the results of a challenge where metaheuristics are developed for multi-mode and multi-project scheduling problems. Zamani (2019) studied the application of the genetic algorithm on a multi-mode resource-constrained project scheduling problem. Many other researchers have studied the application of other metaheuristics that are used in project scheduling, for example, Particle Swarm Optimization and Tabu Search. The aim of this literature review is not to present an exhaustive list of all the works that have been done in this field, but rather to present those that inspired the development of the GA that is proposed in this paper.

The model presented in our study is a new extension of former project scheduling models. To solve it, it is inevitable to develop a novel solving method that takes into account the hypotheses of the problem in the proposed integrated planning model. The new method includes a procedure that schedules the activities of multiple projects and plans different supply chain operations (production, transportation and recycling) in an interactive manner while considering the constraints and hypotheses related to the two parts: project scheduling and supply chain planning.

\subsection{Research objectives}

Figure 1 presents the research framework where the project planning constraints impact the planning of operations in the forward-reverse supply chain and reciprocally the forward-reverse supply chain constraints affect the scheduling of activities in projects. This mutual two-way impact shows the need to integrate the two planning systems, and consequently meet the procurement and environmental commitments through just-in-time delivery of non-renewable resources on the one hand and shipping and recycling of wastes on the other hand. 


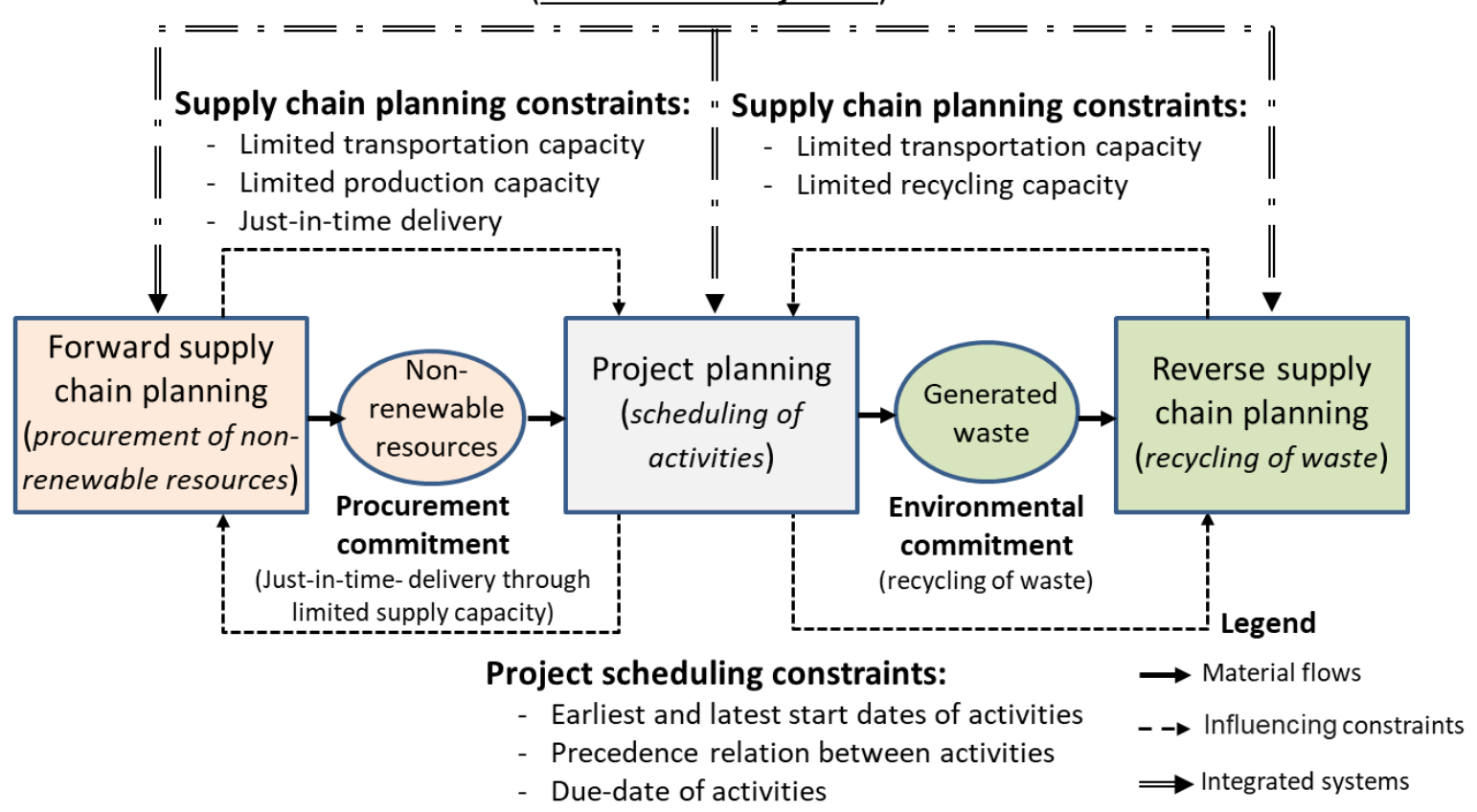

Fig.1 Research framework: an integrated planning system

Based on the discussions in the introductory section and the literature review, we formulate two research objectives:

1. Develop a planning system that integrates project scheduling and supply chain planning in order to create a model that considers supply chain constraints in the scheduling of the project activities and at the same time considers project planning constraints in the planning of the supply chain operations, while meeting procurement commitments (just-in-time delivery through the limited procurement capacity of the suppliers) as well as environmental commitments (recycling of waste).

2. Develop an efficient heuristic-based genetic algorithm to solve instances of the problem, especially for large sizes.

\section{Model development}

\subsection{Problem statement}

In the problem of this study, a set of multiple projects, indexed by $s$, are supposed to be scheduled simultaneously. Every activity $i$ in the projects possesses a processing time $D_{i}$, a due-date $D D_{i}$, an earliest $E T_{i}$ and a latest start $L T_{i}$ dates with a priori known values. We categorize the Finish-to-Start precedence relations between the activities, $F S_{(i, j)}$ as "wait" $\left(N W_{F S(i, j)}=0\right)$ or "no-wait" $\left(N W_{F S(i, j)}=\right.$ 1) precedencies. The "no-wait" relations imply that a successor activity should be processed immediately after the execution of its predecessors, whereas the "wait" precedencies exclude the 
immediate execution of successor activities. Therefore, a lag time $\operatorname{Lag}_{i, j}$, which presents a delay, may exist between the execution of the activities in "wait" relations. In the problem studied, a common pool of renewable resources is shared among multiple projects. We assume that some of the renewable resources, indexed by $r$, hold a significant rental cost, while the others, indexed by $r$, do not have high rental costs. The model of this study aims to minimize the execution cost of the projects by shortening the period during which the high rental cost resources are maintained at the project sites. Both expensive and inexpensive renewable resources have initial available quantities, respectively noted by $I R_{r}^{\prime}$ and $I R_{r}$. However, the model keeps the possibility of extending the capacity of the renewable resources by adding limited supplementary quantities $M R_{r}^{\prime}$ and $M R_{r}$. The demand of the project activities for expensive and inexpensive renewable resources are respectively denoted by $\mathrm{Dr}^{\prime}{ }_{\text {ir }}^{\prime}$ and $\mathrm{Dr}_{\mathrm{ir}}$.

Each activity $i$ may require the non-renewable resources $n r$, which is noted by $\mathrm{Dnr}_{\mathrm{i}, \mathrm{nr}}$. Regarding the non-renewable resources, in order to eliminate their stock and also protect them from different natural or non-natural hazards, these resources are delivered just-in-time (via a supply chain network) to the project worksite. In the model, we assume that the supply of raw materials, indexed by $k$, is constrained by the limited transportation capacity of the suppliers, $F_{C a p}$ (e presents index of suppliers). The manufacturing centres, indexed by $m$, possess one or more production lines $l m$ that have limited production capacities in each time period $t$ of the planning horizon, $I M C_{\operatorname{lnm}(\operatorname{lm}, m), t}$. The production of the items and the ordering of the raw materials are realized according to a given bill of materials $Q_{\left(p_{1}, p_{2}\right)}$, which determines the quantity of a component $p_{1}$ that is used to produce item $p_{2}$. In the network, for environmental responsibility concerns, we assume that there exist individual centres which exclusively recycle the wastes generated on the sites. Besides, we presume that some of the manufacturers may also possess recycling centres with recycling lines. The recycling lines and he recycling centres are respectively indexed by $l r$ and $c$. The recycling lines $l r$ in the recycling centres $c$ possess limited recycling capacity, noted by $I R C_{\ln (l r, c), t}$. The production of products $p m$ and recycling of wastes $w$ require given values of workload that are respectively denoted by $W M_{p m, l m}$ and $W R_{w, l}$. The workload is considered as a given amount of working time that should be dedicated to performing the production or recycling of items. We suppose that the production and recycling centres are flexible enough in adding supplementary capacities in order to increase their responsiveness in meeting requirements.

In our problem, we categorize all the items into two groups and refer to them as "incoming" items, indexed by in $\left(d^{\prime}, p^{\prime}\right)$, and "outgoing" items, indexed by out $(o ", p$ "). The "incoming" items have to do with items that are received in a unit and will be used there. Examples of "incoming" items are raw materials and intermediate products. On the contrary, the "outgoing" items are processed in a unit and will be shipped to the next use destinations. End products of the supply chain and wastes are 
examples of "outgoing" items. For both "incoming" and "outgoing" items, there is a limited storage capacity in the supply chain units. They are respectively noted by $I n C a p_{u}$ and $\mathrm{OutCap}$, where $u$ is the index of units in the supply chain. The storage capacity is considered as the space that is available to store items at different centres in the supply chain. Depending on the space that is occupied by each item $p$, noted by $C f_{p}$, and the limited available warehouse space, a limited quantity of the items can be stored in the supply chain units. It is assumed that the initial and final quantities of the stocks is equal to zero. Furthermore, the transportation capacity of the units in the supply chain is limited. This capacity is denoted by FCap . In both forward and reverse supply chains, there are non-negligible production $\operatorname{Pr} L_{i m(l m, m, p m)}$ and transportation $T L_{f(o, d, p)}$ lead-times. The objective of the model is to minimize the total cost of running the system. Therefore, the model aims to minimize both the project planning costs and the forward-reverse supply chain planning costs. We note that the detailed description of the notations to show the cost terms (as well as all the notations) are provided in section 3.3.

\subsection{Problem formulation}

Table 1 provides the description of the mathematical notations:

Table 1 Indexes, sets, parameters and decision variables

\section{1.a Indexes and sets:}

Indexes and sets related to multi-project scheduling:

S:

I:

$\mathrm{T}$ :

$\mathrm{R}:$

$\mathrm{R}^{\prime}$

$\mathrm{A}_{\mathrm{s}}$ :

$\mathrm{FS}_{(\mathrm{i}, \mathrm{j})}$ :

$\mathrm{NW}_{\mathrm{FS}(\mathrm{i}, \mathrm{j})}$ :

$\alpha_{s(i, j)}:$

$\alpha_{r, s(i, j)}^{\prime}:$ set of projects, indexed by $s$. set of activities, indexed by $i$.

set of time periods, indexed by $t$.

set of inexpensive renewable resources, indexed by $r$.

set of expensive renewable resources, indexed by $r$.

set of activities that belong to project $s,\left(\mathrm{~A}_{\mathrm{s}} \subset \mathrm{I}\right)$.

Finish-to-Start precedence relation between successor activity $j$ and predecessor activity $i$.

1 , if successor activity $j$ in precedence FS begins immediately after ending the predecessor activity $i$. 0 , otherwise. $\mathrm{NW}_{\mathrm{FS}(\mathrm{i}, \mathrm{j})}=1$ and $\mathrm{NW}_{\mathrm{FS}(\mathrm{i}, \mathrm{j})}=0$ respectively represent no-wait and wait precedencies.

link between $i$ and $j$. It is used to relate beginning activity $i$ and ending activity $j$ at worksite $s$.

link between $i$ and $j$, where $i$ is the activity of placing high rental cost renewable 
resource $r^{\prime}$ on project site $s$ and $j$ is the activity of its displacing.

Indexes and sets related to forward and reverse supply chain planning:

* Stared notations are the ones that relate forward and reverse supply chain planning problem to multi-project schedu problem.

$\mathrm{NR}^{*}$ :

set of non-renewable resources (final products of the supply chain network) required on the project sites, indexed by $n r$.

PM: $\quad$ set of items produced by the supply chain, indexed by $p m$.

$\mathrm{K}: \quad$ set of raw materials, indexed by $k$.

$\mathrm{W}^{*}: \quad$ set of waste types, indexed by $w$.

E:

set of suppliers of raw materials, indexed by $e$.

M:

set of manufacturing centres, indexed by $m$.

C:

set of recycling centres, indexed by $c$.

$\mathrm{U}$ :

set to represent all units in the network. It includes the project sites, manufacturing centres, recycling centres and suppliers of raw materials, $U=S \cup M \cup C \cup E$, indexed by $u$.

PT:

set to represent all items in the network.

$\mathrm{F}(\mathrm{o}, \mathrm{d}, \mathrm{p})^{*}:$

set of flows that represent the shipment of item $p$ from origin $o$ to destination $d$, o $\mathrm{e}$ $U, d \in U, p \in P T$, indexed by $f(0, d, p)$.

$\mathrm{IN}\left(\mathrm{d}^{\prime}, \mathrm{p}\right)^{\prime}$ :

set of pairs to link 'incoming" item $p$ ' to destination $d$. Product $p$ ' is used in destination $d^{\prime}, d^{\prime} \in U, p^{\prime} \in P T$, indexed by $i n\left(d^{\prime}, p^{\prime}\right)$.

OUT $(\mathrm{o}, \mathrm{p})$ : $\quad$ set of pairs to link "outgoing" item $p$ " to origin $o$ ". Product $p$ " is sent from origin $o^{\prime \prime}, o^{\prime \prime} \in U-E, p^{\prime \prime} \in P T$, indexed by out $\left(o^{\prime \prime}, p^{\prime \prime}\right)$.

LM: $\quad$ set of production lines, indexed by $\mathrm{lm}$.

LR: $\quad$ set of recycling lines, indexed by $l r$.

LNM $(\mathrm{lm}, \mathrm{m})$ : $\quad$ set of pairs that link production line $l m$ to the manufacturing site $m$ to which it belongs, indexed by $\operatorname{lnm}(l m, m)$.

LNR (lr, c): $\quad$ set of pairs that link recycling line $l r$ to the recycling centre $c$ to which it belongs, indexed by $\ln r(l r, c)$.

IM $(\mathrm{lm}, \mathrm{m}, \mathrm{pm})$ : $\quad$ set of triplets representing the production of item $p m$ in production line $\mathrm{lm}$ at manufacturing centre $m$, indexed by $i m(l m, m, p m)$.

IC (lr, c, w): $\quad$ set of triplets representing the recycling of waste $w$ in recycling line $l r$ at recycling centre $c$, indexed by ic $(l r, c, w)$.

$\beta\left(p_{1}\right): \quad$ set of items that are made out of item $p_{1}$. 


\section{1.b Parameters:}

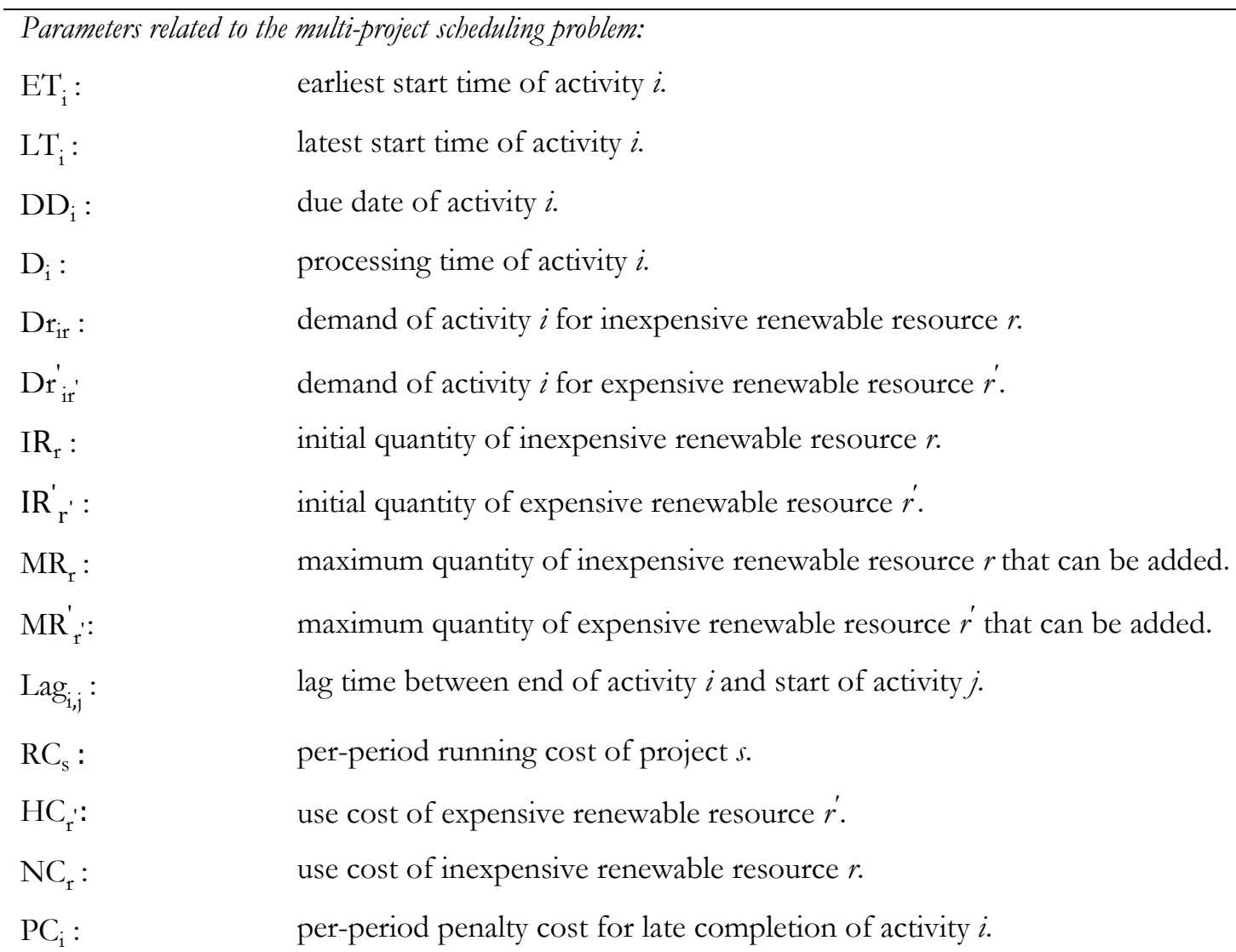

Parameters related to both multi-project scheduling and forward and reverse supply chain planning problems:

$\operatorname{Dnr}_{\mathrm{i}, \mathrm{nr}}$ : $\quad$ demand of activity $i$ for non-renewable resource $n r$.

$\mathrm{WP}_{\mathrm{w}, \mathrm{i}}$ : $\quad$ quantity of waste type $w$ that is generated by activity $i$.

$\mathrm{TC}_{\mathrm{f}(\mathrm{o}, \mathrm{d}, \mathrm{p})}$ : $\quad$ cost for shipping a unit of item $p$ from origin $o$ to destination $d$.

$\mathrm{TL}_{\mathrm{f}(\mathrm{o}, \mathrm{d}, \mathrm{p})}: \quad \quad \quad \quad \quad \quad$ transportation lead-time to ship item $p$ from origin $o$ to destination $d$.

FCap $_{\mathrm{u}}$ : $\quad$ transportation capacity of unit $u$.

Parameters related to forward and reverse supply chain network planning problems:

$\operatorname{InCap}_{\mathrm{u}}$ : $\quad$ maximum capacity for storing the "incoming" items in unit $u$.

OutCap $_{u}$ : maximum capacity for storing the "outgoing" items in unit $u$, excluding the suppliers of the raw materials.

$\operatorname{IMC}_{\operatorname{lnm}(\mathrm{lm}, \mathrm{m}), \mathrm{t}}: \quad$ initial production capacity of line $l m$ in unit $m$ at period $t$.

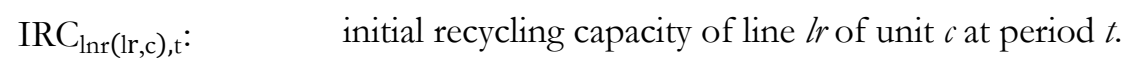

$\mathrm{WM}_{\mathrm{pm}, \mathrm{lm}}$ : $\quad$ workload for producing item $p m$ in line $\mathrm{lm}$.

$\mathrm{WR}_{\mathrm{w}, \mathrm{Ir}}$ : $\quad$ workload for recycling waste $w$ in line $l r$.

$\operatorname{PrL}_{\mathrm{im}(\mathrm{Im}, \mathrm{m}, \mathrm{pm})}: \quad$ lead-time to produce item $p m$ in line $l m$ of manufacturing centre $m$. 
storage cost per unit of item $p, p \in P T$.

$\mathrm{PRC}_{\mathrm{pm}}$ :

production cost per unit of item $p m$.

$\mathrm{RRC}_{\mathrm{w}}$ : recycling cost per unit of waste $w$.

$\mathrm{AP}_{\operatorname{lnm}(\mathrm{Im}, \mathrm{m}):}$ cost for adding a unit of capacity to production line $l m$ in manufacturing centre $m$.

$\mathrm{AR}_{\ln (\mathrm{Ir}, \mathrm{c})}$ cost for adding a unit of capacity to recycling line $l r$ in recycling centre $c$.

$\mathrm{Q}_{\left(\mathrm{p}_{1}, \mathrm{p}_{2}\right)}:$ quantity of component $p_{1}$ that is used in the production of item $p_{2}$ in the bill of materials.

$\mathrm{Cf}_{\mathrm{p}}$ : coefficient that determines the space occupied by a unit of item $p, p \in P T$.

\section{1.c Decision variables}

Decision variables related to the multi-project scheduling problem:

$\mathrm{X}_{\mathrm{it}}$ :

1 if activity $i$ starts at time $t, 0$ otherwise.

$\mathrm{Y}_{\mathrm{it}}$ :

1 if activity $i$ is being processed over time $t, 0$ otherwise.

$Z_{\mathrm{i}}$ :

lateness of activity $i$.

$\mathrm{V}_{\mathrm{i}}$ : start time of activity $i$.

$\mathrm{AR}_{\mathrm{rt}}$ : quantity of inexpensive renewable resource $r$ only added at time $t$.

$\mathrm{AR}_{\mathrm{r}^{\prime} \mathrm{t}}$ : quantity of expensive renewable resource $r$ only added at time $t$.

Decision variables related to both multi project scheduling and forward and reverse supply chain network planning problems: $\mathrm{TQ}_{\mathrm{f}(\mathrm{o}, \mathrm{d}, \mathrm{p}), \mathrm{t}}$ : transported quantity of item $p$ from origin $o$ to destination $d$ at time $t, o \in U, d \in U, p$ є PT.

Decision variables related to the forward and reverse supply chain network planning problem:

$\operatorname{SIn}_{\text {in }\left(\mathrm{d}^{\prime}, \mathrm{p}^{\prime}\right), \mathrm{t}}$ : $\quad$ stock quantity of "incoming" item $p$ received at destination $d$ at time $t, d^{\prime} \in U, p^{\prime} \mathrm{e}$ PT.

SOut $_{\text {out }(\circ ", \mathrm{p}), \mathrm{t}}$ : $\quad$ stock quantity of "outgoing" item $p$ sent from origin $o$ at time $t, o^{\prime \prime} \in U-E, p$ " $\in$ PT, indexed by out $\left(0^{\prime \prime}, p^{\prime \prime}\right)$.

$\mathrm{PQ}_{\mathrm{im}(\mathrm{Im}, \mathrm{m}, \mathrm{pm}), \mathrm{t}} \quad$ quantity of item $p m$ produced in production line $l m$ of unit $m$ at time $t$.

$\mathrm{RQ}_{\mathrm{ir}(\mathrm{Ir}, \mathrm{c}, \mathrm{w}), \mathrm{t}}$ quantity of waste $w$ recycled in recycling line $t r$ at recycling centre $c$ at time $t$.

$\mathrm{ALP}_{\operatorname{lnm}(\mathrm{Im}, \mathrm{m}), \mathrm{t}}$ : quantity of capacity added to production line $l m$ at manufacturing centre $m$ only at ti $t$.

$\mathrm{ALR}_{\operatorname{lnr}(\mathrm{Ir}, \mathrm{c}), \mathrm{t}}:$ quantity of capacity added to recycling line $I r$ at recycling centre $c$ only at time $t$.

The mathematical model of the problem is presented below: 


\section{Objective Function:}

The objective function of the model (Equation 1) aims to minimize the total cost of the system. The cost terms in the first brackets correspond to the project planning costs while those in the second brackets correspond to the supply chain planning costs. The project planning costs include respectively i) the running cost of projects, ii) costs related to the use of expensive renewable resources, iii) penalty cost for the late completion of activities, iv) the cost of adding supplementary inexpensive renewable resources, and v) the cost of adding supplementary expensive renewable resources. Regarding the supply chain planning costs of the model, they are composed of i) the transportation cost of items from origins to destinations of use, ii) storage cost of ("incoming") items that are used in a unit, iii) storage cost of ("outgoing") items that are sent from a unit, iv) production cost of products, v) recycling costs of wastes, vi) cost of adding supplementary production capacities and, vii) cost of adding supplementary recycling capacities.

$$
\begin{aligned}
& \text { Min OF }=\left[\sum_{\mathrm{s}} \sum_{(\mathrm{i}, \mathrm{j}) \in \alpha_{\mathrm{s}(\mathrm{i}, \mathrm{j})}}\left(\mathrm{V}_{\mathrm{j}}+\mathrm{D}_{\mathrm{j}}-\mathrm{V}_{\mathrm{i}}\right) \mathrm{RC}_{\mathrm{s}}+\sum_{\mathrm{s}} \sum_{\mathrm{r}^{\prime}} \sum_{(\mathrm{i}, \mathrm{j}) \in \alpha_{\mathrm{r}, \mathrm{s}(\mathrm{i}, \mathrm{j})}^{\prime}}\left(\mathrm{V}_{\mathrm{j}}+\mathrm{D}_{\mathrm{j}}-\mathrm{V}_{\mathrm{i}}\right) \mathrm{HC}_{\mathrm{r}^{\prime}}++\sum_{\mathrm{i}} \mathrm{Z}_{\mathrm{i}} \mathrm{PC}_{\mathrm{i}}+\right. \\
& \left.\sum_{\mathrm{r}} \sum_{\mathrm{t}} \mathrm{AR}_{\mathrm{rt}} \mathrm{NC}_{\mathrm{r}}+\sum_{\mathrm{r}^{\prime}} \sum_{\mathrm{t}} \mathrm{AR}_{\mathrm{r}^{\prime} \mathrm{t}}^{\prime} \mathrm{HC}_{\mathrm{r}^{\prime}}\right]+ \\
& {\left[\sum_{\mathrm{f}(\mathrm{o}, \mathrm{d}, \mathrm{p})} \sum_{\mathrm{t}} \mathrm{TQ}_{\mathrm{f}(\mathrm{o}, \mathrm{d}, \mathrm{p}), \mathrm{t}} \mathrm{TC}_{\mathrm{f}(\mathrm{o}, \mathrm{d}, \mathrm{p}), \mathrm{t}}+\sum_{\text {in(d', } \left.\mathrm{p}^{\prime}\right)} \sum_{\mathrm{t}} \mathrm{SIn}_{\mathrm{in}\left(\mathrm{d}^{\prime}, \mathrm{p}^{\prime}\right), \mathrm{t}} \mathrm{SC}_{\mathrm{p}}+\right.} \\
& \sum_{\text {out }\left(\mathrm{o}^{\prime \prime}, \mathrm{p}\right. \text { ") }} \sum_{\mathrm{t}} \mathrm{SOut}_{\text {out }(\mathrm{o} ", \mathrm{p} \text { "),t }} \mathrm{SC}_{\mathrm{p}} \quad+\quad \sum_{\mathrm{im}(\mathrm{lm}, \mathrm{m}, \mathrm{pm})} \sum_{\mathrm{t}} \mathrm{PQ}_{\mathrm{im}(\mathrm{lm}, \mathrm{m}, \mathrm{pm}), \mathrm{t}} \mathrm{PRC}_{\mathrm{pm}} \quad+ \\
& \sum_{\text {ir (lc,c,w) }} \sum_{\mathrm{t}} \mathrm{RQ}_{\mathrm{ir}(\mathrm{lc}, \mathrm{c}, \mathrm{w}), \mathrm{t}} \mathrm{PRL}_{\mathrm{w}}+ \\
& \left.\sum_{\operatorname{lnm}(\operatorname{lm}, \mathrm{m})} \sum_{\mathrm{t}} \mathrm{ALP}_{\operatorname{lnm}(\operatorname{lm}, \mathrm{m}), \mathrm{t}} \mathrm{AP}_{\operatorname{lnm}(\operatorname{lm}, \mathrm{m})}+\sum_{\ln (1 \mathrm{r}, \mathrm{c})} \sum_{\mathrm{t}} \mathrm{ALR}_{\operatorname{lnr}(\mathrm{lr}, \mathrm{c}), \mathrm{t}} \mathrm{AR}_{\ln r(\mathrm{lr}, \mathrm{c})}\right]
\end{aligned}
$$

The above objective function is solved subject to the constraints presented in Table 2.

Table 2 The constraint functions of the model

\section{Explanation}

Multi project planning constraints:

Constraint (2) states that an

$$
\sum_{\mathrm{t}=\mathrm{ET}_{\mathrm{i}}}^{\mathrm{LT}_{\mathrm{i}}} \mathrm{X}_{\mathrm{it}}=1
$$

activity should be started at a

$$
\forall i \in I
$$

time between its earliest and

latest start time.

Constraint (3) assures that the $\quad \sum_{\mathrm{t}=\mathrm{ET}_{\mathrm{i}}}^{\mathrm{LT}_{\mathrm{i}}+\mathrm{D}_{\mathrm{i}}-1} \mathrm{Y}_{\mathrm{it}}=\mathrm{D}_{\mathrm{i}}$

sum of the periods during which $\forall i \in \mathrm{I}$

an activity is running is equal to

its processing time.

With regards to the lag time,

$$
\begin{aligned}
& V_{j} \geq V_{i}+D_{i}+L_{a g} \\
& \forall(i, j) \in \mathrm{FS}_{(i, j)}, N_{F S(i, j)}=0
\end{aligned}
$$


constraint (4) and constraint (5) $\quad \mathrm{V}_{\mathrm{j}}=\mathrm{V}_{\mathrm{i}}+\mathrm{D}_{\mathrm{i}}$

respectively define the start time $\forall(\mathrm{i}, \mathrm{j}) \in \mathrm{FS}_{(\mathrm{i}, \mathrm{j})}, \mathrm{NW}_{\mathrm{FS}(\mathrm{i}, \mathrm{j})}=1$

of successor activities under a

"wait" and "no-wait" conditions.

Constraints (6) and (7) link the $\quad \sum_{\mathrm{k}=\mathrm{t}}^{\mathrm{t}-1+\mathrm{D}_{\mathrm{i}}} \mathrm{Y}_{\mathrm{it}} \geq \mathrm{D}_{\mathrm{i}} \mathrm{X}_{\mathrm{it}}$

decision variables $\mathrm{X}_{\mathrm{it}}, \mathrm{Y}_{\mathrm{it}}$ and $\mathrm{V}_{\mathrm{i}} . \quad \forall \mathrm{i} \in \mathrm{I}, \forall \mathrm{t} \in\left\{\mathrm{ET}_{\mathrm{i}}, \ldots, \mathrm{LT}_{\mathrm{i}}\right\}$

$\mathrm{V}_{\mathrm{i}}=\sum_{\mathrm{t}=\mathrm{ET} \mathrm{T}_{\mathrm{i}}}^{\mathrm{LT} \mathrm{T}_{\mathrm{i}}} \mathrm{t} \mathrm{X}_{\mathrm{it}}$

$\forall i \in \mathrm{I}$

Constraint (8) determines the

$\mathrm{Z}_{\mathrm{i}} \geq \mathrm{V}_{\mathrm{i}}+\mathrm{D}_{\mathrm{i}}-\mathrm{DD}_{\mathrm{i}}$

lateness that may occur in the

$\forall i \in I$

completion of activities

Constraints (9) and (10)

$\sum_{\mathrm{i} \in \mathrm{I}} \mathrm{Dr}_{\mathrm{it}} \mathrm{Y}_{\mathrm{it}} \leq \mathrm{IR}_{\mathrm{r}}+\mathrm{AR}_{\mathrm{rt}}$

respectively guarantee the

satisfaction of activities' demand

for respectively inexpensive and

$\forall \mathrm{r} \in \mathrm{R}, \forall \mathrm{t} \in \mathrm{T}$

$\sum_{\mathrm{i} \in \mathrm{I}} \mathrm{Dr}_{\mathrm{it}}^{\prime} \mathrm{Y}_{\mathrm{it}} \leq \mathrm{IR}_{\mathrm{r}^{\prime}}^{\prime}+\mathrm{AR}_{\mathrm{r}^{\prime} \mathrm{t}}^{\prime}$

$\forall r^{\prime} \in R^{\prime}, \forall t \in T$

expensive renewable resources

by the allocation of the initial

quantity of these resources and

the quantity that may be added.

Expressions (11) and (12)

$\mathrm{AR}_{\mathrm{rt}} \leq \mathrm{MR}_{\mathrm{r}}$

respectively guarantee that the

$\forall \mathrm{r} \in \mathrm{R}, \forall \mathrm{t} \in \mathrm{T}$

$\mathrm{AR}_{\mathrm{r}^{\prime} \mathrm{t}}^{\prime} \leq \mathrm{MR}_{\mathrm{r}}^{\prime}$

supplementary quantities of

inexpensive and expensive

$\forall r^{\prime} \in R^{\prime}, \forall t \in T$

renewable resources cannot

exceed a given maximum value.

Constraints to relate project scheduling and forward and reverse supply chain planning problems:

Constraint (13) satisfies the

$\sum_{\mathrm{f}(\mathrm{o}, \mathrm{d}, \mathrm{p}) \in \mathrm{F}(\mathrm{o}, \mathrm{d}, \mathrm{p}) \mid \mathrm{d}=\mathrm{s}, \mathrm{p}=\mathrm{nr}} \mathrm{TQ}_{\mathrm{f}(\mathrm{o}, \mathrm{d}, \mathrm{p}), \mathrm{t}-\mathrm{TL}_{\mathrm{f}(\mathrm{o}, \mathrm{d}, \mathrm{p})}}=$

demand of the project activities

$\sum_{\mathrm{ieA}} \mathrm{Anr}_{\mathrm{i}, \mathrm{nr}} \mathrm{X}_{\mathrm{it}}$

of worksites for the non-

$\forall \mathrm{s} \in \mathrm{S}, \forall \mathrm{nr} \in \mathrm{NR}, \forall \mathrm{t} \in \mathrm{T}$

renewable resources to be

delivered just in time.

Equation (14) shows the balance

$\operatorname{SOut}_{\text {out(o", p"), t- } 1}+\sum_{\mathrm{i} \in \mathrm{I}_{\mathrm{S}}} \mathrm{X}_{\mathrm{it}} \mathrm{WP}_{\mathrm{w}, \mathrm{i}}=$

of flows for the wastes that are

$\sum_{\mathrm{f}} \mathrm{TQ}_{\mathrm{f}(\mathrm{o}, \mathrm{d}, \mathrm{p}), \mathrm{t}}+\operatorname{SOut}_{\text {out }\left(\mathrm{o}^{\prime \prime}, \mathrm{p} "\right), \mathrm{t}}$ 
sent from the worksites.

$\forall \mathrm{s} \in \mathrm{S}, \forall \mathrm{w} \in \mathrm{W}, \forall t \in \mathrm{T}$

$\forall$ out $\left(\mathrm{o}^{\prime \prime}, \mathrm{p}\right) \in \operatorname{OUT}\left(\mathrm{o}^{\prime \prime}, \mathrm{p}\right) \mid \mathrm{o}=\mathrm{s}, \mathrm{p}=\mathrm{w}$

Forward and reverse supply chain planning constraints:

Similar to equation (14),

SOut $_{\text {out }\left(o^{\prime \prime}, p^{\prime \prime}\right), t-1}+$

equation (15) shows the balance

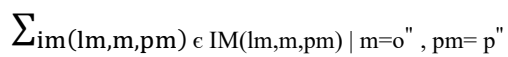

of flows in the supply chain for

$P Q_{i m(i m, m, p m), t-P r L} \operatorname{Pim}_{(\mathrm{lm}, \mathrm{m}, \mathrm{pm})}=$

"outgoing" items. This

constraint is expressed for the

$\sum_{\mathrm{f}(\mathrm{o}, \mathrm{d}, \mathrm{p}) \in \mathrm{F}(\mathrm{o}, \mathrm{d}, \mathrm{p}) \mid \mathrm{o}=\mathrm{m}, \mathrm{p}=\mathrm{pm}} \mathrm{TQ}_{\mathrm{f}(\mathrm{o}, \mathrm{d}, \mathrm{p}), \mathrm{t}}+$

produced products that are

transported from the

manufacturing centres.

SOut $_{\text {out }}\left(\mathrm{o} ", \mathrm{p}^{\prime \prime}\right), \mathrm{t}$

$\forall \mathrm{m} \in \mathrm{M}, \forall \mathrm{pm} \in \mathrm{PM}, \forall \mathrm{t} \in \mathrm{T}$

$\forall \operatorname{out}\left(\mathrm{o}^{\prime \prime}, \mathrm{p}\right) \in \operatorname{OUT}\left(\mathrm{o}^{\prime \prime}, \mathrm{p}\right) \mid \mathrm{o}=\mathrm{o}, \mathrm{p}=\mathrm{pm}$

Equations (16), (17) and (18)

$\operatorname{SIn}_{\text {in }}\left(\mathrm{d}^{\prime}, \mathrm{p}^{\prime}\right), \mathrm{t}-1+$

represent the balance of flows

for "incoming" items

respectively for raw materials

received at manufacturing

centres, intermediate products

received in the manufacturing

centres and the wastes that

should be recycled in the

$\sum_{\mathrm{f}(\mathrm{o}, \mathrm{d}, \mathrm{p}) \in \mathrm{F}(\mathrm{o}, \mathrm{d}, \mathrm{p}) \mid \mathrm{d}=\mathrm{m}, \mathrm{p}=\mathrm{k}} \mathrm{TQ}_{\mathrm{f}(\mathrm{o}, \mathrm{d}, \mathrm{p}), \mathrm{t}-\mathrm{TL}_{\mathrm{f}(\mathrm{o}, \mathrm{d}, \mathrm{p})}}=\operatorname{SIn}_{\mathrm{in}\left(\mathrm{d}^{\prime}, \mathrm{p}^{\prime}\right), \mathrm{t}}+$

$\sum_{\mathrm{b} \in \beta\left(\mathrm{P}_{1}\right) \mid \mathrm{P}_{1}=\mathrm{k}}$

$\sum_{\text {im }(\mathrm{lm}, \mathrm{m}, \mathrm{pm}) \in \operatorname{IM}(\mathrm{lm}, \mathrm{m}, \mathrm{pm}) \mid \mathrm{m}=\mathrm{d}^{\prime}, \mathrm{pm}=\mathrm{b}} \mathrm{PQ}_{\mathrm{im}(\mathrm{im}, \mathrm{m}, \mathrm{pm}), \mathrm{t}} \mathrm{Q}_{\left(\mathrm{p}^{\prime}, \mathrm{b}\right)}$

$\forall \mathrm{m} \in \mathrm{M}, \forall \mathrm{k} \in \mathrm{K}, \forall \mathrm{t} \in \mathrm{T}$

$\forall \operatorname{in}\left(d^{\prime}, p^{\prime}\right) \in \operatorname{IN}\left(d^{\prime}, p^{\prime}\right) \mid d^{\prime}=m, p^{\prime}=k$

$\operatorname{SIn}_{\text {in }}\left(\mathrm{d}^{\prime}, \mathrm{p}^{\prime}\right), \mathrm{t}-1+$

$\sum_{f(o, d, p) \in F(o, d, p) \mid d=m, p=p m} T Q_{f(o, d, p), t-} \operatorname{TL}_{f(o, d, p)}=\operatorname{SIn}_{i n}\left(d^{\prime}, p^{\prime}\right), t$

recycling centres.

$+$

$\sum_{\mathrm{b} \in \beta\left(\mathrm{P}_{1}\right) \mid \mathrm{P}_{1}=\mathrm{pm}}$

$\sum_{\text {im }(\mathrm{lm}, \mathrm{m}, \mathrm{pm}) \in \operatorname{IM}(\mathrm{lm}, \mathrm{m}, \mathrm{pm}) \mid \mathrm{m}=\mathrm{d}^{\prime}, \mathrm{pm}=\mathrm{b}} \mathrm{PQ}_{\mathrm{im}(\mathrm{im}, \mathrm{m}, \mathrm{pm}), \mathrm{t}} \mathrm{Q}_{\left(\mathrm{p}^{\prime}, \mathrm{b}\right)}$

$\forall \mathrm{m} \in \mathrm{M}, \forall \mathrm{pm} \in \mathrm{PM}, \forall \mathrm{t} \in \mathrm{T}$

$\forall \operatorname{in}\left(d^{\prime}, p^{\prime}\right) \in \operatorname{IN}\left(d^{\prime}, p^{\prime}\right) \mid d^{\prime}=m, p^{\prime}=p m$

$\operatorname{SIn}_{\text {in }}\left(\mathrm{d}^{\prime}, \mathrm{p}^{\prime}\right), \mathrm{t}-1+$

$\sum_{\mathrm{f}(\mathrm{o}, \mathrm{d}, \mathrm{p}) \in \mathrm{F}(\mathrm{o}, \mathrm{d}, \mathrm{p}) \mid \mathrm{d}=\mathrm{c}, \mathrm{p}=\mathrm{w}} \mathrm{TQ}_{\mathrm{f}(\mathrm{o}, \mathrm{d}, \mathrm{p}), \mathrm{t}-\mathrm{TL}_{\mathrm{f}(\mathrm{o}, \mathrm{d}, \mathrm{p})}}=\operatorname{SIn}_{\mathrm{in}\left(\mathrm{d}^{\prime}, \mathrm{p}^{\prime}\right), \mathrm{t}}+$

$\sum_{\mathrm{ic}(\mathrm{lr}, \mathrm{c}, \mathrm{w})} \mathrm{RQ}_{\mathrm{ic}(\mathrm{lr}, \mathrm{c}, \mathrm{w}), t}$

$\forall \mathrm{c} \in \mathrm{C}, \forall \mathrm{W} \in \mathrm{W}, \forall \mathrm{t} \in \mathrm{T}$

$\forall \operatorname{in}\left(d^{\prime}, p^{\prime}\right) \in \operatorname{IN}\left(d^{\prime}, p^{\prime}\right) \mid d^{\prime}=c, p^{\prime}=w$

Constraint (19) shows that the

$\sum_{\text {im(lm,m,pm) }} \mathrm{PQ}_{\mathrm{im}(\mathrm{im}, \mathrm{m}, \mathrm{pm}), \mathrm{t}} \mathrm{WM}_{\mathrm{pm}, \mathrm{b}} \leq \mathrm{IMC}_{\mathrm{lnm}(\mathrm{lm}, \mathrm{m}), \mathrm{t}}+$

production of the items is

$\mathrm{ALP}_{\operatorname{lnm}(\mathrm{lm}, \mathrm{m}), \mathrm{t}}$

$\forall \operatorname{lnm}(\mathrm{lm}, \mathrm{m}), \mathrm{t} \in \mathrm{LNM}(\mathrm{lm}, \mathrm{m}), \forall \mathrm{t} \in \mathrm{T}$

limited by the available

production capacities (including 
the capacities that may be

added).

Expression (20) indicates that

$\sum_{\mathrm{ic}(\mathrm{lr}, \mathrm{c}, \mathrm{w})} \mathrm{RQ}_{\mathrm{ic}(\mathrm{lr}, \mathrm{c}, \mathrm{w}), \mathrm{t}} \mathrm{WR}_{\mathrm{w}, \mathrm{lr}} \leq$

the recycling of wastes is

$\mathrm{IRC}_{\operatorname{lnr}(\mathrm{lr}, \mathrm{c}), \mathrm{t}}+\mathrm{ALR}_{\operatorname{lnr}(\mathrm{l}, \mathrm{c}), \mathrm{t}}$

constrained by the initial

$\forall \operatorname{lnr}(\operatorname{lr}, \mathrm{c}), \mathrm{t} \in \operatorname{LNR}(\mathrm{lr}, \mathrm{c}), \forall \mathrm{t} \in \mathrm{T}$

recycling capacity plus the

supplementary capacity that may

be added.

Expressions (21) and (22)

$\sum_{\mathrm{p}} \operatorname{SIn}_{\mathrm{in}\left(\mathrm{d}^{\prime}, \mathrm{p}^{\prime}\right) \mid \mathrm{d}=\mathrm{u}, \mathrm{t}} \mathrm{Cf} \mathrm{p}_{\mathrm{p}^{\prime}} \leq \operatorname{InCap}_{\mathrm{u}}$

present the constraints related to

$\forall \mathrm{u} \in \mathrm{U}, \forall \mathrm{t} \in \mathrm{T}$

storage capacities, respectively,

$\sum_{\mathrm{p}}$ SOut $_{\text {out }(\mathrm{o} ", \mathrm{p} ") \mid \mathrm{o}=\mathrm{u}, \mathrm{t}} \mathrm{SCf}_{\mathrm{p}} \leq$ OutCap $_{\mathrm{u}}$

for "incoming" and "outgoing"

$\forall \mathrm{u} \in \mathrm{U}, \forall \mathrm{t} \in \mathrm{T}$

items.

Constraint (23) deals with the

$\mathrm{TQ}_{\mathrm{f}(\mathrm{o}, \mathrm{d}, \mathrm{p}) \mid \mathrm{o}=\mathrm{u}, \mathrm{t}} \leq \mathrm{FCap}_{\mathrm{u}}$

limited transportation capacity.

$\forall \mathrm{u} \in \mathrm{U}, \forall \mathrm{f}(\mathrm{u}, \mathrm{d}, \mathrm{p}) \in \mathrm{F}(\mathrm{o}, \mathrm{d}, \mathrm{p}), \forall \mathrm{t} \in \mathrm{T}$

Constraints (24) and (25) state

$\operatorname{SIn}_{\text {in }\left(\mathrm{d}^{\prime}, \mathrm{p}^{\prime}\right), \mathrm{t}}=0$

the initial and final stock level of

the items.

$\forall \operatorname{in}\left(d^{\prime}, \mathrm{p}^{\prime}\right) \in \operatorname{IN}\left(\mathrm{d}^{\prime}, \mathrm{p}^{\prime}\right), \mathrm{t} \in\{0, \mathrm{~T}\}$

SOut $_{\text {out }\left(0^{\prime \prime}, p^{\prime \prime}\right), t}=0$

$\forall \operatorname{out}\left(\mathrm{o}^{\prime \prime}, \mathrm{p} "\right) \in \operatorname{OUT}\left(\mathrm{o}^{\prime \prime}, \mathrm{p} "\right), \mathrm{t} \in\{0, \mathrm{~T}\}$

\section{Constraints on decision}

variables:

And, constraints (26), (27) and

$0 \leq \mathrm{Y}_{\mathrm{it}} \leq 1$

(28) present the types of the

$\forall i \in \mathrm{I}, \forall \mathrm{t} \in \mathrm{T}$

$U_{i}, V_{i}, A_{r t}, A_{r^{\prime} t}^{\prime}, T_{f(o, d, p), t}, \operatorname{SIn}_{\text {in }\left(d^{\prime}, p^{\prime}\right), t}, \operatorname{SOut}_{\text {out }\left(o^{\prime \prime}, p^{\prime \prime}\right), t}$,

decision variables.

$$
\begin{aligned}
& \mathrm{ALP}_{\operatorname{lnm}(\mathrm{lm}, \mathrm{m}), \mathrm{t}}, \mathrm{ALR}_{\ln (\mathrm{l}, \mathrm{c}), \mathrm{t}}, \mathrm{PQ}_{\mathrm{im}(\mathrm{im}, \mathrm{m}, \mathrm{pm}), \mathrm{t}}, \mathrm{RQ}_{\mathrm{ic}(\mathrm{lr}, \mathrm{c}, \mathrm{w}), t} \geq 0 \\
& \forall i \in \mathrm{I}, \forall \mathrm{t} \in \mathrm{T}, \forall \mathrm{f}(\mathrm{o}, \mathrm{d}, \mathrm{p}) \in \mathrm{F}(\mathrm{o}, \mathrm{d}, \mathrm{p}), \forall \mathrm{in}\left(\mathrm{d}^{\prime}, \mathrm{p}^{\prime}\right) \in \mathrm{IN}\left(\mathrm{d}^{\prime}, \mathrm{p}^{\prime}\right) \text {, } \\
& \forall \operatorname{out}\left(\mathrm{o}^{\prime \prime}, \mathrm{p}\right) \text { є } \operatorname{OUT}\left(\mathrm{o}^{\prime \prime}, \mathrm{p}\right) \text {, } \\
& \operatorname{im}(\operatorname{lm}, \mathrm{m}, \mathrm{pm}), \mathrm{t} \in \operatorname{IM}(\mathrm{lm}, \mathrm{m}, \mathrm{pm}), \mathrm{t} \text {, } \\
& \forall i c(l r, c, w) \in I C(l r, c, w), \forall r \in R, \forall r^{\prime} \in R^{\prime}
\end{aligned}
$$

$\mathrm{X}_{\mathrm{it}} \in\{0,1\}$ 
In the mathematical model presented in Section 3.3, we used a different mode to determine some indexes, including $f(o, d, p), \operatorname{in}\left(d^{\prime}, p^{\prime}\right)$ and $\operatorname{out}\left(o^{\prime \prime}, p^{\prime \prime}\right)$ indexes. This mode of indexing provides some specificities to our mathematical model. They are outlined hereunder.

1) Determination of $f(o, d, p)$ triplet as an index to establish a mathematical model which is independent of the network structure of the supply chain

Generally, the structure of supply chain networks is determined by the number of the network layers and the type of relationships that exist between the actors. In a three-stage supply chain network, which is composed of raw material suppliers, manufacturing centres and customers, the relationships between any two actors can be considered as the flows that exist between two actors to transport an item from an actor to the other. In such a network, the decision variable to show the transported quantity of raw material $k$ from supplier $e$ (in the first layer) to manufacturing centre $m$ (in the second layer) can be determined by a typical variable $\mathrm{G}_{\mathrm{e}, \mathrm{m}, \mathrm{k}}$. To show the material flows of product $p$ between the second and third layers, that is, between manufacturing centres $m$ and customers $s$, it is necessary to define a new variable, such as $\mathrm{Q}_{\mathrm{m}, \mathrm{s}, \mathrm{p}}$. In extending the mathematical model of this threelayer problem to a model with four layers or more, it will be necessary to determine extra decision variables and add expressions to formulate the material flows between the new layers. In our formulation mode, the determination of index $f(o, d, p)$ that represents all the potential material flows, which exist between the actors (transporting an item $p$ from origin $o$ to destination $d$ ) as well as the decision variables related to this index (decision variable $\mathrm{TQ}_{\mathrm{f}(\mathrm{o}, \mathrm{d}, \mathrm{p}), \mathrm{t}}$ related to the quantity of the transported items between the actors) makes the presentation and application of the model not limited to the problems with a fixed number of layers in the supply chain network. We note that the justification of the indexing mode used in the mathematical model is to help managers, who are not experts in OR, to create supply chain networks with desired number of layers through graphical interfaces of a Decision Support Tool (DST) and to optimize the supply chain according to the constraints of the optimization model. In the context of the CRIBA project, to make the theoretical framework of this paper useable for managers, we developed a web-based DST. The description of the architecture, licence and interfaces of the DSS is not within the scope of this paper.

2) Determination of in $\left(d^{\prime}, p^{\prime}\right)$ and out $\left(o^{\prime \prime}, p^{\prime \prime}\right)$ indexes to build the stock decision variables Using $f(o, d, p)$ index and $\mathrm{TQ}_{\mathrm{f}(\mathrm{o}, \mathrm{d}, \mathrm{p}), \mathrm{t}}$ decision variables to model the flow of the materials, an adapted approach is required to model and calculate the stock level of the different items in the supply chain network. We determined in $\left(d^{\prime}, p^{\prime}\right)$ and out $\left(o^{\prime \prime}, p^{\prime \prime}\right)$ indexes. They respectively represent the items that are received in a unit and those that are sent from a unit. These indexes are used to establish the related stock variables, that is, $\operatorname{SIn}_{\text {in( }\left(d^{\prime}, p^{\prime}\right), t}$ and $\operatorname{SOut}_{\text {out }\left(o^{\prime \prime}, p^{\prime \prime}\right), t}$.

\subsection{An illustrative example}


A typical instance of the problem is shown in Figure 2. In Figure 2.a, there are four identical projects to be scheduled. The forward-reverse supply chain network is composed of five categories of actors that include the suppliers of the raw materials, the manufacturers of the intermediate products, the manufacturers of the final products, the worksites and the recycling centres. Figure 2.b depicts the activity network of the projects. In order to minimize the cost related to the hiring of renewable resources with high rental costs, the model of this study aims to shorten the period during which these resources (cranes in the case of this study) are maintained at the project sites. For this purpose, we minimize the duration between two specific activities that are added to represent the installation and removal (hiring and returning) of these resources. We note that the Activity-On-Node diagram of the project activities includes neither predecessor activities that determine the supply of the nonrenewable resources to the project sites nor the successor activities that present the collection of wastes that are generated at worksites after the execution of the activities. Indeed, including these activities in the Activity-On-Node diagram can generally lead to two consequences :1- it forces the planning system to supply the non-renewable resources or collect the generated wastes at predetermined dates. So, it reduces the flexibility in the planning and does not let the model to plan to optimality the supply operations as well as the operations related to the collection and recycling of the wastes. 2- It can lead to more unnecessary transportations (to supply the non-renewable resources to project worksites or to ship the generated wastes to the project worksites), and consequently it can increase the cost in the system. Whereas, by excluding these activities from the Activity-On-Node diagram, the demands for the non-renewable resources in the project sites as well as the quantities of the wastes that should be transported to the recycling centres can be regrouped. So, the transportation operations can be planned and performed to optimality. 


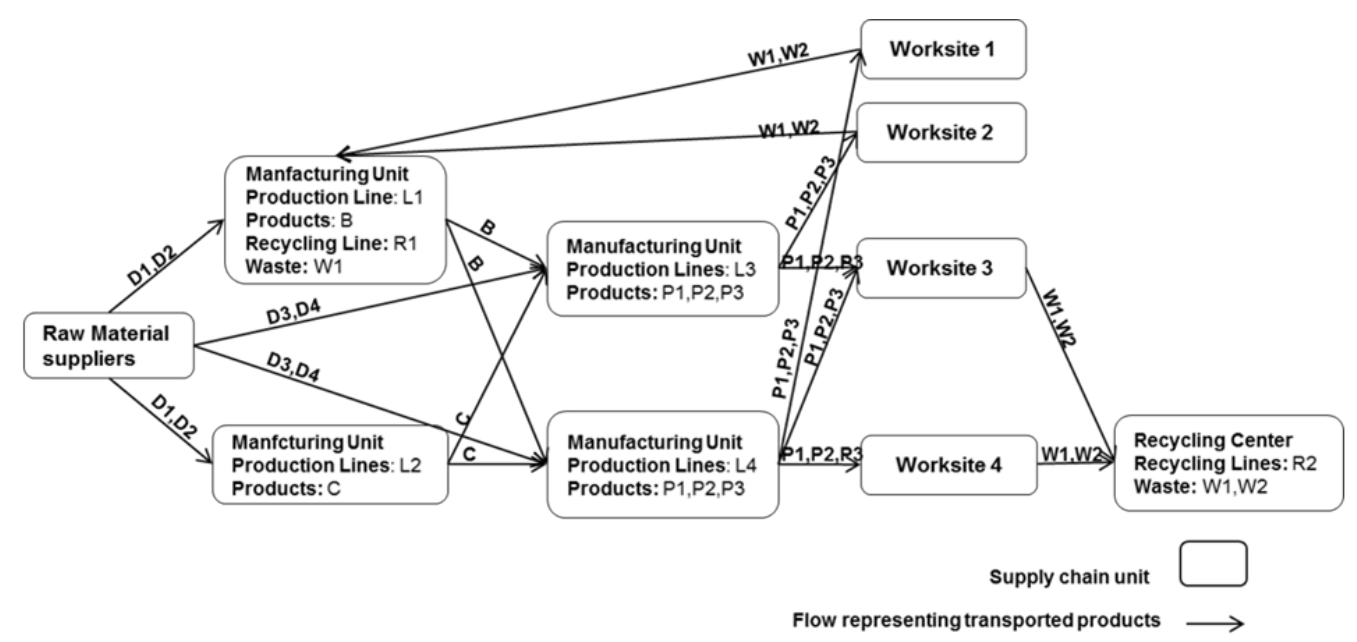

Fig.2.a A typical instance to present the material flows between network actors

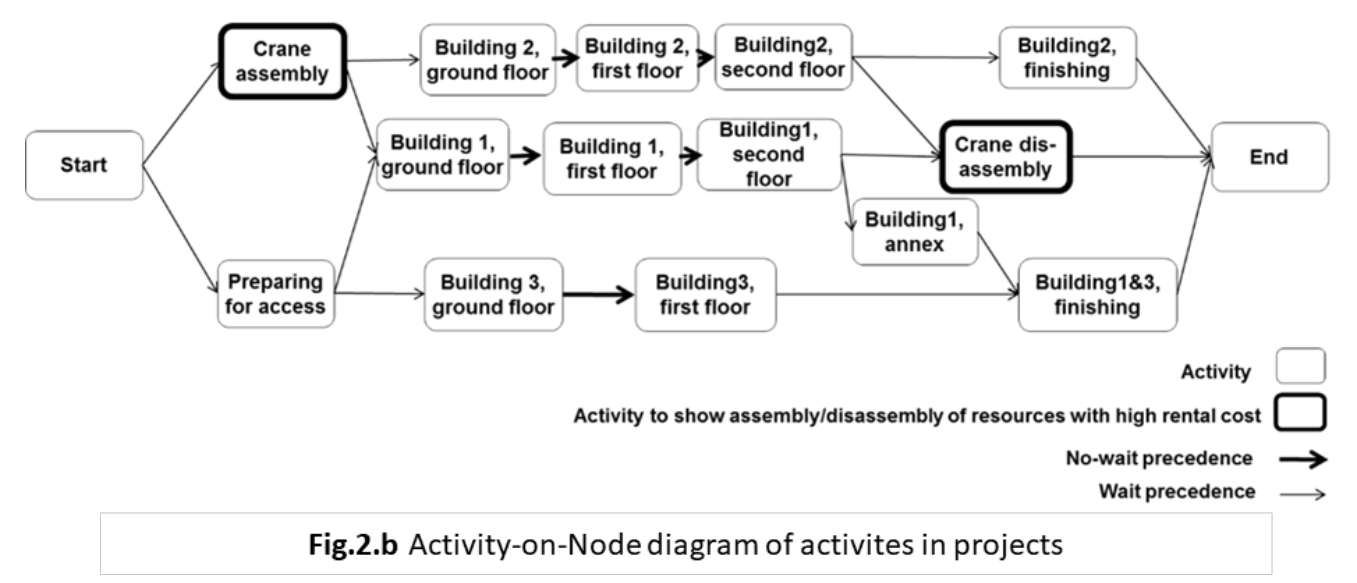

Fig.2 A figurative instance of the model

\section{Solution method}

To solve the proposed model, a two-phase approach including a pre-processing phase and a main phase is applied:

\subsection{Critical Path Method-based pre-processing phase}

In real-world applications, the data required for the scheduling of projects are generally estimated and set by experts. In this study, in order to rectify the estimated earliest and latest start dates of the activities, we employ the forward and backward procedures of the Critical Path Method (CPM) presented by (Ahuja, 1976). The modified earliest and latest start dates enhance the main phase of the resolution method by generating the feasible candidates for the start time of activities. We note that the modified earliest (latest) finish date of each activity is calculated by adding its processing time to its modified earliest (latest) start date. 


\subsection{Genetic algorithm-based main phase}

The genetic algorithm, introduced by Holland (1976), maintains a population of solutions whose size is specified by Population Size. In the GA, an individual, which presents a candidate solution, is characterized by a set of variables known as genes. Genes are joined into a string to form a chromosome. The individuals of the population are evaluated according to their fitness function (elitism). A set of operators, known as crossover and mutation, are issued to generate diversity in the population and to create new individuals. Each of the operators is employed according to appropriate rates that are respectively termed as Crossover Rate and Mutation Rate. The GA proceeds toward an optimal solution until a predefined convergence criterion is reached. The details of our GA are described in the following sub-sections.

\subsubsection{Solution representation}

The illustration of individual $\Lambda$ in the GA is given in Figure3. " $N$ " contains a permutation of activities. It is worth noting that since in our problem the renewable resources are shared among multiple projects, we regroup the activities of the projects to make a mega project and create a universal set of activities. " $N{ }^{4}$ " is a permutation list that includes all the activities that belong to multiple projects. We note that in the $N^{4}$ list, start and end activities exist for each project, where these activities respectively do not possess predecessor and successor activities. Using the " $N$ " list, " $S N^{\Lambda}$ " presents a precedence-feasible activity list where each activity is placed on the list after all its predecessors. The feasible start dates to execute the activities are calculated via a procedure that converts the $S N^{4}$ list to a feasible schedule. The generated start dates are represented by vector " $V$ ". The matrices from " $Z$ " to "SOut" in individual $\Lambda$ record the values for the corresponding decision variables in the model. The mechanisms to determine the activities' schedule and the values for the decision variables are described in section 4.2.2.

$$
\left[\begin{array}{c}
\mathrm{N}^{\wedge}(I) \\
S N^{\wedge}(I) \\
\mathrm{V}^{\wedge}(I) \\
Z^{\wedge}(I) \\
A R^{\wedge}\left(R^{\prime} \times T\right) \\
A R^{\wedge}(R \times T) \\
T Q^{\wedge}(U \times U \times P T \times T) \\
P Q^{\wedge}((L M \times M \times P M) \\
R Q^{\wedge}(L R \times C \times W) \\
A L P^{\wedge}(L M \times M \times T) \\
A L R^{\wedge}(L R \times C \times T) \\
S I^{\wedge}(U \times P T \times T) \\
S O u t^{\wedge}(U \times P T \times T)
\end{array}\right]
$$

Fig.3 Presentation of an individual in the search algorithm with its key arrays 


\subsubsection{Initial population generation}

The main intention of our search procedure is to determine the feasible start date for the activities of projects by considering the interactions between the project scheduling constraints and forward supply chain planning constrains, and then to propagate the impact of the constructed solutions on the reverse supply chain to generate optimized solutions for its variables. Figure 4 describes this mechanism. As mentioned in section 4.2.1, each solution comprises the precedence-feasible activity list $S N$. An adapted Serial Schedule Generation Scheme (SSGS) is used to transform the $S N$ list to a list of feasible start dates. Using the following principles, it schedules the activities at the precedence and resource-feasible start time:

i. Each activity should be started at a time point between its modified earliest start time and latest start time.

ii. The successor activities with no-wait precedencies must be started immediately after the accomplishment of their predecessors. In situations where the required renewable resources are not totally available, the amount of the deficiency will be added.

iii. The successor activities with wait precedencies can be started only when the required renewable resources are completely available. In the cases where the renewable resources are not available, the needed quantities can be added at any time in a point varying from the eligible modified earliest and latest start time. To assign a start time to an activity in the $S N$ list, a cost indicator (CI) is used. The value of the indicator at time $t$ is calculated as in expression (29):

$$
\mathrm{CI}=\mathrm{CI}_{1}+\mathrm{CI}_{2}+\mathrm{CI}_{3}
$$

where, $\mathrm{CI}_{1}$ is the total cost of adding the resources at time $t$ and over the processing time of the activity, $\mathrm{CI}_{2}$ is the penalty cost for the late completion of the activity, and $\mathrm{CI}_{3}$ is an inner penalty cost to penalize the time point $t$ if the added quantity of resources exceeds the maximum allowed additional value. This value is determined according to the preference of the decision makers. Among the potential time points, the one that holds a minimum value for the $\mathrm{CI}$ is chosen as the start time of the activity.

iv. In any case, if the required amount of renewable resources exceeds the maximum additional capacity, the solution will be penalized by adding a penalty cost in the fitness function.

v. If the calculated start dates cause the production and transportation capacities in the forward supply chain to be violated, the constructed schedules are rejected, and the search algorithm generates another schedule until it finds one that satisfies the capacity constraints as well. 


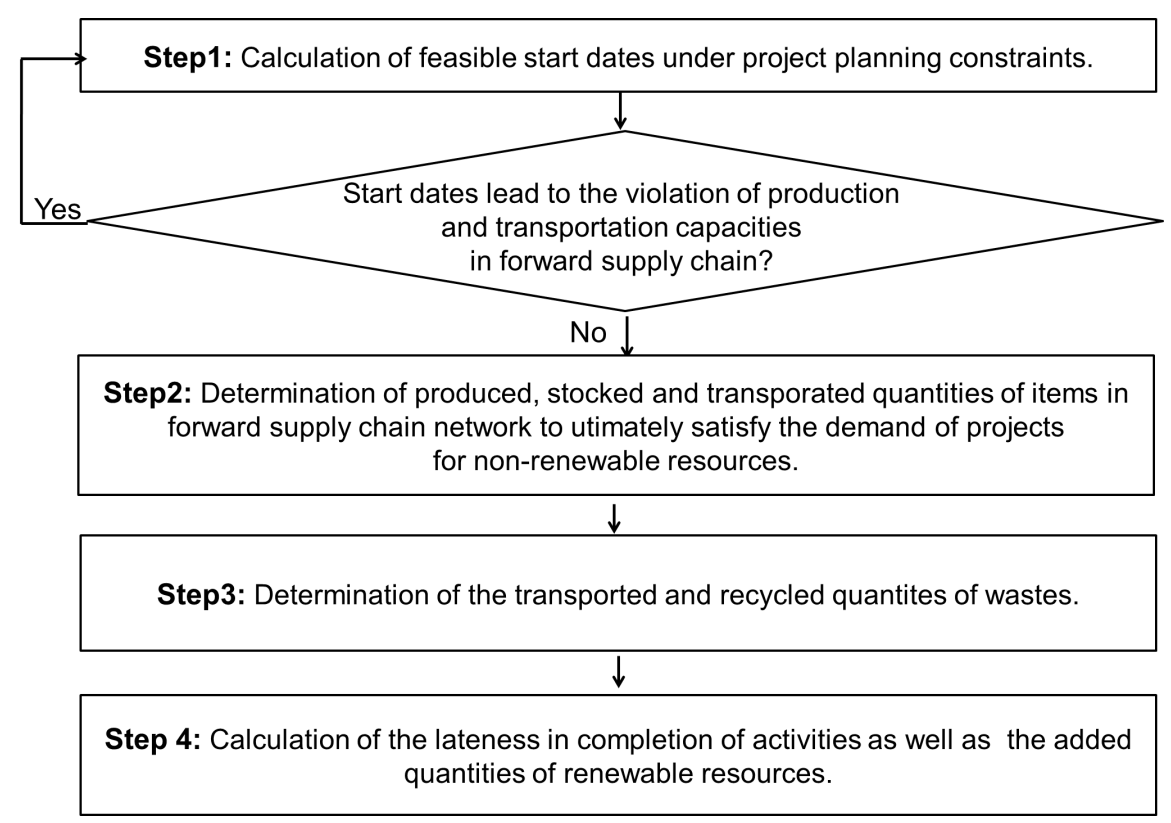

Fig.4 Working mechanism to initialize the GA individuals

In essence, the solution method presented in this paper schedules the critical activities in their feasible dates, while satisfying the constraints. The non-critical activities can be floated over an interval defined between their modified earliest and latest start dates. Our method aims to assign a start date to non-critical activities in a way that the constraints are guaranteed, and the total cost is minimized.

Considering the activities that start at different time points, the total demand for non-renewable resources at every time point $t$ is calculated. The generated demands for the non-renewable resources are transmitted level by level, from the project sites to the manufacturing centres and then to the raw material suppliers. Taking the transportation lead-time into account, the demanded quantity of the non-renewable resources is transported to the project worksites just-in-time through the flows from potential manufacturers. To initialize the stock values of the "outgoing" items in a corresponding manufacturer, a random value between zero and the value of the generated demand is drawn. This generated stock should be used at upcoming time periods. The stock level at the end and beginning period of the planning horizon must be zero. The quantities for "incoming" items are calculated based on the bill of materials and they are supplied to the use destinations by potential intermediate product manufacturers or raw material suppliers.

Considering the demanded quantities of the non-renewable resources as well as the probable stocks, the total production workload is calculated and the required supplementary capacities are added to the production lines, while considering the lead-times. The production of the required intermediate products as well as the supply of raw materials are dealt with in a similar manner. 
To calculate the values of the variables in the reverse supply chain, the potential destinations for shipping the wastes are first found and then a random fraction of the generated wastes is associated with the corresponding flows while taking the transportation lead-time into account. The solutions which violate the transportation capacity are penalized in the fitness function.

At the last step, the lateness of the activities and the total quantity of the added renewable resources are calculated, and their values are recorded in their corresponding matrices.

\subsubsection{Fitness function}

The fitness of individuals is determined by the summation of two terms that include: i) the cost of the solution calculated according to the objective function and ii) the penalty cost that is imposed by the violation of a solution from soft constraints of the model. These constraints involve the stock capacity constraints of the forward supply chain units and the capacity constraints of the reverse supply chain as well as the constraints related to maximum quantity of renewable resources that can be added. Equation 30 presents the fitness function terms, where $\eta$ and $\mu$ are weight factors between 0 and $1, \eta+\mu=1, b$ is the index of the soft constraints, $\rho$ and $\delta$ are respectively a penalty coefficient and a violation factor.

Fitness function $=$ Min $[\eta($ Objective function value $)+\mu($ Total penalty cost from solutions violating the soft constraints $)]=\operatorname{Min}\left[\eta(O F)+\mu\left(\sum_{b} \rho_{b} \delta_{b}\right)\right]$

Depending on the flexibility of organizations in dealing with the violation in soft constraints, the decision makers are able to determine different values of $\rho$ to makemedium to large influence on the optimization results. To determine the value of the violation factoro, we propose to use expression 31. In this formula, if solution $\left(\mathrm{x}_{1}, \mathrm{x}_{2}, \ldots, \mathrm{x}_{\mathrm{k}}\right)$ does not make constraint $\mathrm{g}$ to violate the right-handside value $g_{0}$, the violation factor $\delta$ is equal to 0 . Otherwise, it is equal to $\frac{g\left(x_{1}, x_{2}, \ldots, x_{k}\right)}{g_{0}}-1$. The term $\frac{\mathrm{g}\left(\mathrm{x}_{1}, \mathrm{x}_{2}, \ldots, \mathrm{x}_{\mathrm{k}}\right)}{\mathrm{g}_{0}}$ presents a relative value and considers the violation value in its scale. So, using expression 33, not only small and large violations have not been penalized equally, but also, they are penalized according to their violation values in their scales.

$\delta\left\{g\left(x_{1}, x_{2}, \ldots, x_{k}\right) \leq g_{0}\right]=\left\{\begin{array}{ll}0 & g\left(x_{1}, x_{2}, \ldots, x_{k}\right) \leq g_{0} \\ \frac{g\left(x_{1}, x_{2}, \ldots, x_{k}\right)}{g_{0}}-1 & g\left(x_{1}, x_{2}, \ldots, x_{k}\right) \geq g_{0}\end{array}\right\}$

\subsubsection{Elite solution selection and search operators}

Selection is the process of choosing individuals (parents) from the population for reproduction. The Roulette wheel operator, discussed in (Holland 1976), is employed to select elite solutions for crossover. Using this operator, if the fitness of individual $\Lambda$ is $\mathrm{f}_{\Lambda}$, the selection probability of $\Lambda$ is $\mathrm{p}_{\Lambda}=\mathrm{f}_{\Lambda} / \sum_{\eta=1}^{\mathrm{Npop}} \mathrm{f}_{\eta}$, where Npop is the number of individuals in the population. Order 1 crossover 
(OX1) is used as the reproduction operator (Tseng and Liang 2006). Using OX1, each of the new solutions inherits the genes between two crossover points from one of the parents in the same position as they are placed in the parent's chromosome. The remaining genes are taken from the other parent in the order they emerge in that parent's chromosome, starting from the first position following the second crossover point and ignoring the elements that have already been presented in the offspring. This operator is applied to the " $\mathrm{N}$ " list of the algorithm.

Furthermore, a hybrid mutation between the swap, reversion and insertion operators has been employed to make the algorithm capable of searching for neighbouring solutions. The swap operator chooses two genes from the chromosome at random, then it swaps their values. The inversion mutation chooses a part of a chromosome. Then, it orders the genes of the selected part inversely. The insertion operator specifies two genes of the chromosome. Without changing the order, it replaces the one next to the other.

\subsubsection{New population sizing and stop criteria}

The new individuals produced by crossover and mutation are added to the population list. The individuals are sorted according to their fitness. The fittest individuals are chosen to form new populations. The number of the chosen individuals is equal to the size of the population. The research procedure terminates once a maximum number of iterative runs is attained.

\section{Computational experiments}

\subsection{Data setting}

The pattern for data generation and the dimension of the instances are outlined in Appendix A. As presented in the appendix, the data are generated using statistical distributions within bounds. The values for the bounds of the statistical distributions are estimated by the CRIBA project coordinators. It is worth noting that the generation of random data enables to eliminate the impact of the data. It also helps to validate the efficiency of the resolution method in finding optimized solutions for random instances.

\subsection{Parameter setting for the proposed GA}

Since the performance of the metaheuristics significantly depends on the values of their parameters, finding the optimum setting for the parameters will be inevitable. The Taguchi method is a fractional factorial experimentation approach that performs efficiently in determining robust values for variables (parameters) of experiments. It relies on two main concepts: i) orthogonal arrays and ii) Signal-to-Noise ratio. The inclusion of the orthogonal arrays in the Taguchi model enables to take into account different levels of factors and to conduct a limited number of experiments while 
preserving a sufficient amount of the information. In a GA possessing four factors (population size (Npop), number of iterations (Nit), crossover rate $(\mathrm{CrR})$ and mutation rate $(\mathrm{MuR}))$ and three levels (lower, moderate and upper values), the orthogonal array L9(3**4) is used to perform the Taguchi experiments. The Signal-to-Noise $(\mathrm{S} / \mathrm{N})$ ratio measures the robustness of the responses (see (Taguchi, 1986)). The term signal is associated with the response values whereas the term noise measures the variability in the responses. The $(\mathrm{S} / \mathrm{N})$ ratio is calculated as in expression 32 , where $Y$ represents the responses and $n$ is the number of experiments.

$\mathrm{S} / \mathrm{N}=-10 \log \left(\sum_{\mathrm{i}} \mathrm{Y}_{\mathrm{i}}^{2} / \mathrm{n}\right)$

Since the results of the $\mathrm{S} / \mathrm{N}$ analysis, can be totally dominated by the magnitude of responses, the normalization of the value of responses will be inevitable. In this study, we employ the Relative Percentage Deviation (RPD) index to rescale the responses (Vallada and Ruiz 2011), using expression 33.

Relative Percentage Deviation (RPD) $=\frac{\mid \text { Response }_{\text {Agorithm }}-\text { Response }_{\text {Best }} \mid}{\text { Response }_{\text {Best }}} \times 100$

To run the $\mathrm{S} / \mathrm{N}$ analysis, three sizes of the model instances including small, medium and large ones are generated, relying on principles presented in Appendix A. Different levels of the GA parameters for each size of the instances are presented in Table 3. Using Table 3 and the orthogonal array L9, the values for different parameters in each size category of the model are set (see column "Factor levels" in Table 4). The genetic algorithm is executed with the values assigned to the parameters. The column "Response value" in Table4presents the response values (fitness values) of the best solution found by the algorithm. Based on the response values, the "RPD" is calculated. The RDP results are used to conduct the $\mathrm{S} / \mathrm{N}$ analysis and to determine the robust values of the parameters of the genetic algorithm in each size category of the instances. Table 5 summarizes the results. We note that Minitab 16.0 is used to perform the $\mathrm{S} / \mathrm{N}$ analysis.

Furthermore, the time elapsed to perform each of the experimentations is reported in the column "Time" of Table 4. As can be seen, increasing the number of iterations generally increases the computational time. It is worth noting that the number of iterations is not the only factor that determines the duration of the resolution time. Another driving factor is the algorithm's effort in finding and maintaining feasible solutions when the constructed solutions are rejected because of the infeasibility.

Table 3 Levels of the Taguchi design for different factors of the instance problems

\begin{tabular}{lcccc}
\hline Project & \multicolumn{4}{c}{ (Upper, Moderate, Lower) values for driving factors of the algorithm } \\
\cline { 2 - 5 } size & Mutation rate & Crossover rate & Number of & Population size \\
& $\mathbf{( M u R )}$ & $(\mathbf{C r R})$ & iterations & (Npop) \\
& & & $(\mathbf{N I t})$ & $(20,25,30)$ \\
Small & $(0.2,0.25,0.3)$ & $(0.6,0.7,0.75)$ & $(25,30,35)$ &
\end{tabular}



Medium
$(0.2,0.3,0.35)$
$(0.65,0.75,0.8)$
$(80,90,100)$
$(70,85,100)$
Large
$(0.2,0.35,0.4)$
$(0.75,0.8,0.85)$
$(180,195,210)$
$(150,175,200)$

Table 4 Taguchi experiments for small, medium and large sizes of the problem instances

\begin{tabular}{|c|c|c|c|c|c|c|c|}
\hline \multicolumn{8}{|c|}{ Instance size: Small } \\
\hline \multirow{2}{*}{ Test } & \multicolumn{4}{|c|}{ Factor levels } & \multirow{2}{*}{$\begin{array}{c}\text { Response } \\
\text { value }\end{array}$} & \multirow[t]{2}{*}{ RPD } & \multirow{2}{*}{$\begin{array}{c}\text { CPU } \\
\text { time (s) }\end{array}$} \\
\hline & MuR & CrR & NIt & Npop & & & \\
\hline 1 & 0.2 & 0.7 & 25 & 20 & 91596.52 & 0 & 38 \\
\hline 2 & 0.25 & 0.7 & 30 & 20 & 91596.52 & 0 & 21 \\
\hline 3 & 0.35 & 0.6 & 35 & 20 & 91596.52 & 0 & 32 \\
\hline 4 & 0.35 & 0.7 & 25 & 25 & 91596.52 & 0 & 23 \\
\hline 5 & 0.25 & 0.75 & 30 & 25 & 91896.52 & 0.326454 & 28 \\
\hline 6 & 0.25 & 0.6 & 35 & 25 & 91896.52 & 0.326454 & 29 \\
\hline 7 & 0.2 & 0.75 & 25 & 30 & 91896.52 & 0.326454 & 27 \\
\hline 8 & 0.35 & 0.75 & 30 & 30 & 91896.52 & 0.326454 & 27 \\
\hline 9 & 0.2 & 0.6 & 35 & 30 & 91596.52 & 0 & 18 \\
\hline \multicolumn{8}{|c|}{ Instance size: Medium } \\
\hline \multirow{3}{*}{ Test } & \multicolumn{4}{|c|}{ Factor levels } & \multirow{3}{*}{$\begin{array}{c}\text { Response } \\
\text { value }\end{array}$} & \multirow[t]{3}{*}{ RPD } & \multirow{3}{*}{$\begin{array}{c}\text { CPU } \\
\text { time } \\
(s)\end{array}$} \\
\hline & MuR & CrR & NIt & Npop & & & \\
\hline & & & & & & & \\
\hline 1 & 0.2 & 0.75 & 100 & 100 & 214963.04 & 1.4839664 & 804 \\
\hline 2 & 0.2 & 0.8 & 90 & 85 & 214528.04 & 1.2786030 & 712 \\
\hline 3 & 0.3 & 0.8 & 80 & 100 & 211819.70 & 0 & 727 \\
\hline 4 & 0.35 & 0.75 & 80 & 85 & 215443.04 & 1.7105742 & 620 \\
\hline 5 & 0.3 & 0.75 & 90 & 100 & 215848.04 & 1.9017745 & 590 \\
\hline 6 & 0.3 & 0.65 & 100 & 85 & 214963.04 & 1.4839664 & 691 \\
\hline 7 & 0.35 & 0.8 & 100 & 70 & 214528.04 & 1.2786030 & 705 \\
\hline 8 & 0.35 & 0.65 & 90 & 70 & 215848.04 & 1.9017745 & 756 \\
\hline 9 & 0.2 & 0.65 & 80 & 70 & 215848.04 & 1.9017745 & 414 \\
\hline
\end{tabular}

Instance size: Large

\begin{tabular}{|c|c|c|c|c|c|c|c|}
\hline \multirow[b]{2}{*}{ Test } & \multicolumn{4}{|c|}{ Factor levels } & \multirow{3}{*}{$\begin{array}{c}\text { Response } \\
\text { value }\end{array}$} & \multirow{3}{*}{ RPD } & \multirow{3}{*}{$\begin{array}{l}\text { CPU } \\
\text { time } \\
\text { (s) }\end{array}$} \\
\hline & MuR & CrR & NIt & Npop & & & \\
\hline & & & & & & & \\
\hline 1 & 0.25 & 0.8 & 180 & 150 & 426286.45 & 1.091285 & 4593 \\
\hline 2 & 0.4 & 0.75 & 195 & 200 & 425649.05 & 0.940129 & 4743 \\
\hline 3 & 0.4 & 0.85 & 210 & 150 & 422890.31 & 0.285912 & 4431 \\
\hline
\end{tabular}




$\begin{array}{cccccccc}\mathbf{4} & 0.35 & 0.75 & 210 & 175 & 424080.06 & & \\ & & & & & 6 & 0.568054 & 4613 \\ \mathbf{5} & 0.25 & 0.75 & 210 & 200 & 423143.4 & 0.345930 & 2697 \\ \mathbf{6} & 0.4 & 0.8 & 180 & 175 & 427379.73 & & \\ & & & & & 3 & 1.350551 & 4210 \\ \mathbf{7} & 0.35 & 0.85 & 180 & 200 & 421684.66 & & \\ & & & & & 6 & 0 & 5150 \\ \mathbf{8} & 0.35 & 0.8 & 195 & 150 & 421852.3 & 0.039753 & 3527 \\ \mathbf{9} & 0.25 & 0.85 & 195 & 175 & 422780.06 & & \\ & & & & & 6 & 0.259767 & 4366\end{array}$

Table 5 Calibration of the parameters of the genetic algorithm for the instance problems

\begin{tabular}{ccccc}
\hline Size of the instance & \multicolumn{4}{c}{ Value for driving factors of the algorithm } \\
\cline { 2 - 5 } problems & MuR & CrR & NIt & Npop \\
\hline Small size & 0.25 & 0.75 & 25 & 30 \\
Medium size & 0.2 & 0.8 & 100 & 85 \\
Large size & 0.35 & 0.85 & 195 & 150 \\
\hline
\end{tabular}

\subsection{Numerical results: analysis on the convergence and performance of the algorithm}

The random instances (small, medium and large size instances) generated in section 5.2and the results reported in Table 5 are used to study the convergence of the algorithm. Figure5depicts how the proposed algorithm comes into a convergence. As can be seen, the algorithm has almost a quick convergence in the small-size problem, whereas in medium- and large-size problems, the convergence happens in a reasonable duration of time.
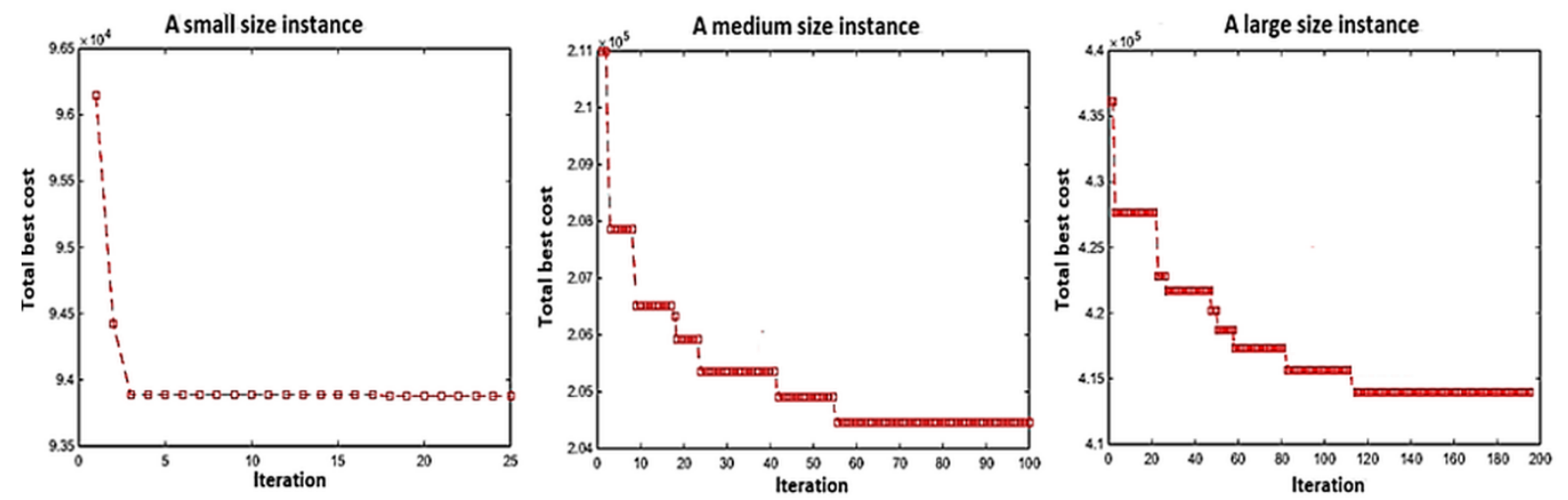

Fig.5 Convergence of the algorithm in different instances using the Taguchi design results 
The performance of the algorithm is investigated from two perspectives: The time elapsed to find results and The quality of results.

To investigate the algorithm performance from the perspective of the elapsed time, the resolution time of the genetic algorithm is compared with the resolution time of the mathematical model by Branch \& Bound algorithm of the Cplex solver. For this purpose, the random instances (including small, medium and large sizes) that are generated in section 5.2 are used. The resolution time by the Cplex solver in the small-and medium-size instances is respectively 4 and 1265 seconds. In the large case, the solver ends up after 17940 seconds (4 hours and 59 minutes) without returning any solutions. On the other hand, the resolution time for solving the same instances by the proposed algorithm is 16 seconds, 699 seconds and 4442 seconds respectively in small, medium and large sizes. As the results show, the resolution time by the genetic algorithm is much shorter than the resolution time of the mathematical model of the problem by the Cplex solver. It must be mentioned that the mathematical model and the algorithm are respectively coded in the Cplex solver version 12.6.1 and Matlab software R2014b. Furthermore, the experiments are carried out on a notebook with Intel ${ }^{\circledR}$ Core i7 CPU, $2.20 \mathrm{GHz}$ processor with a memory of $8 \mathrm{~GB}$.

Regarding the quality of results, 75 more instances (25 instances for each of the small, medium and large sizes) have been generated. To evaluate the performance of the algorithm, the gap between the results obtained from the GA and the results obtained from the resolution of the proposed mathematical model by the Cplex solver is calculated for each of the instances using formulation (34), (Niaki et al. 2015) . Since the resolution of the model by the Cplex solver is traceable for small and medium instances, the results of the application of the proposed algorithm on 50 instances of these sizes are used to calculate the Gap indicator. Furthermore, formulation (35) is used to compare the best solution of the initial population (BI) with the best solution of the algorithm (BA). The results are summarized in Table 6.

$$
\begin{aligned}
& \text { Gap }=\frac{\text { Genetic Algorithm }}{\text { Result }} \text { cplex }_{\text {Result }} \times 100 \\
& \text { cplex }_{\text {Result }} \\
& \text { Improvement }=\frac{\text { BI- BA }}{\text { BI }} \times 100
\end{aligned}
$$

Table 6 Value of the performance indictors in different size of the problem

\begin{tabular}{cccccc}
\hline \multirow{3}{*}{ Test } & \multicolumn{5}{c}{ Problem size } \\
\cline { 2 - 6 } & \multicolumn{2}{c}{ Small } & \multicolumn{2}{c}{ Medium } & Large \\
\cline { 2 - 6 } & Gap & Improve- & Gap & Improve- & Improve \\
& $\mathbf{( \% )}$ & ment (\%) & $\mathbf{( \% )}$ & ment (\%) & $\begin{array}{c}- \text { ment } \\
(\%)\end{array}$ \\
\hline 1 & 1.0 & 2.9 & 1.5 & 1.2 & 5.1
\end{tabular}




\begin{tabular}{|c|c|c|c|c|c|}
\hline 2 & 0.9 & 0.8 & 0.4 & 6.1 & 4.9 \\
\hline 3 & 1.0 & 0.7 & 4.3 & 9.0 & 2.5 \\
\hline 4 & 0.8 & 2.3 & 1.5 & 7.2 & 3.6 \\
\hline 5 & 0.4 & 2.7 & 1.5 & 5.1 & 3 \\
\hline 6 & 1.3 & 1.8 & 2.3 & 5.6 & 7.7 \\
\hline 7 & 1.0 & 3.0 & 1.5 & 9.5 & 4.9 \\
\hline 8 & 1.9 & 1.09 & 3.9 & 5.4 & 3.2 \\
\hline 9 & 0.6 & 0.7 & 2.4 & 5.5 & 8.9 \\
\hline 10 & 0.1 & 1.7 & 2.8 & 8.3 & 4.8 \\
\hline 11 & 0.6 & 2.7 & 0.7 & 1.05 & 3.5 \\
\hline 12 & 0.4 & 3.2 & 2.4 & 4.3 & 9.5 \\
\hline 13 & 0.3 & 0.1 & 0.2 & 1.3 & 3.5 \\
\hline 14 & 0.08 & 2.9 & 1.7 & 3.7 & 4.3 \\
\hline 15 & 0.5 & 3.2 & 0.3 & 5.3 & 0.4 \\
\hline 16 & 0.4 & 0.7 & 1.6 & 3.8 & 2.2 \\
\hline 17 & 0.3 & 0.8 & 2.0 & 3.4 & 7.1 \\
\hline 18 & 0.3 & 0.8 & 0.2 & 9.8 & 2.3 \\
\hline 19 & 0.05 & 0.6 & 1.5 & 6.9 & 2.4 \\
\hline 20 & 0.9 & 3.3 & 0.5 & 3.0 & 9 \\
\hline 21 & 0.2 & 0.6 & 1.9 & 5.8 & 2.7 \\
\hline 22 & 0.04 & 2.1 & 1.6 & 5.4 & 0.7 \\
\hline 23 & 0.3 & 3.3 & 0.2 & 1.5 & 2.4 \\
\hline 24 & 0.4 & 1.1 & 2.3 & 4.1 & 2.4 \\
\hline 25 & 0.08 & 0.6 & 0.7 & 5.1 & 0.7 \\
\hline Min & 0.04 & 0.1 & 0.2 & 1.05 & 0.4 \\
\hline Max & 1.9 & 3.3 & 4.3 & 9.8 & 9.5 \\
\hline Mean & 0.55 & 1.75 & 1.6 & 5.1 & 4.1 \\
\hline
\end{tabular}

The results presented in Table 6 show that the ranges of the gap for the small and medium instances are respectively $[0.04,1.9]$ and $[0.2,4.3]$. On the other hand, the improvement indicator in smalland medium-size instances respectively belongs to $[0.1,3.3]$ and $[1.05,9.8]$. As can be seen, the averages calculated in different instances for the improvement indicator are small values $(1.75 \%$, $5.1 \%$ and $4,9 \%$ respectively in small, medium and large size instances). This fact shows that the initialization procedure of the GA makes the algorithm capable of starting from optimized solutions with good enough quality. On the other hand, the maximum value of the gap in small and medium cases is respectively equal to $1.9 \%$ and $4.3 \%$, while the average of the gap in these instances is $0.55 \%$ and $1.6 \%$. Considering these values, one can state that the genetic algorithm is capable of 
providing appropriate results in different instances of the problem. In a nutshell, the small value of the gap indicator and the good quality of the solutions obtained by the algorithm confirm that the proposed resolution method is efficient and able to find appropriate solutions.

\section{Conclusion}

The conclusion of this study is presented under three sub-sections: summary, limitations, and future research perspectives.

\subsection{Summary}

This paper aims to study an optimization model for planning a set of multiple projects considering material procurement and environmental commitments. The material procurement commitments are satisfied thanks to the just-in-time delivery of the non-renewable resources to the project worksites, subject to the limited transportation and production capacities of suppliers. Regarding the environmental commitments, they are met by the collection and recycling of the wastes that are generated at the project sites. These commitments are obtained by proposing a modelling framework that enables to integrate the project planning and forward-reverse supply chain systems. The idea for this integration stems from the fact that the project planning constraints impact the planning of the supply chain operations (production, transportation and recycling), and reciprocally the forwardreverse supply chain constraints (as well as the just-in-time delivery of non-renewable resources) affect the scheduling of activities in projects.

A new two-phased procedure is developed to solve the instances of the proposed model. It includes a pre-processing phase based on the CPM method and a main phase based on the genetic algorithm. Given that the performance of the metaheuristics depends on the values given to their parameters, the Taguchi method has been employed to define robust values for the parameters of the proposed GA. The performance of the algorithm in the generation of results is evaluated using two indicators, namely, gap and improvement indicators. The modelling framework and resolution method contribute to responding to the requirements of a French project (called CRIBA) in thermal renovation of buildings. The data to carry out the experiments are set by coordination experts of the CRIBA project. Computational experiments show that the proposed algorithm consistently produces high-quality solutions in reasonable computational times.

\subsection{Limitations}

The results showed that our resolution method allows finding high quality solutions. However, using this method, decision makers have some intermediate choices (such as determining the value of penalty coefficients) to make to get a good solution. 


\subsection{Future research perspectives}

For future research works, uncertainty can be integrated in different parameters of the model such as the duration of the activities, the transportation and production capacities or the demand of the activities for different renewable and non-renewable resources. The model can also be extended by integrating the assumptions on different modes of transportation, discount levels for purchasing the materials as well as the possibility of executing the activities in multi-mode. Furthermore, a deficiency can still be seen in the optimization models of the project scheduling problems with environmentally responsible attitudes. Therefore, future research may consider other hypotheses to minimize the amount of the greenhouse gas emissions in the supply chain network. The study is still open to be developed by the application of other metaheuristics as well as different initialization procedures in the metaheuristics. Finally, the comparison of the performance between resolution procedures can be of interest.

Appendix A Data generation pattern

\begin{tabular}{|c|c|c|c|}
\hline \multirow[b]{2}{*}{ Parameters } & \multicolumn{3}{|c|}{ Problem size } \\
\hline & $\begin{array}{l}\text { Small (1 project) } \\
( \\
\left.16^{*} \times 3^{* *} \times 3^{* * *} \times 35^{* * * *}\right)\end{array}$ & $\begin{array}{l}\text { Medium ( } 2 \text { projects) } \\
(32 \times 4 \times 3 \times 35)\end{array}$ & $\begin{array}{l}\text { Large }(3 \text { projects }) \\
(64 \times 4 \times 3 \times 35)\end{array}$ \\
\hline $\mathrm{Dnr}_{\mathrm{i}, \mathrm{nr}}$ & $\mathrm{DU}^{*} \sim(0,2)$ & $\mathrm{DU} \sim(0,3)$ & $\mathrm{DU} \sim(0,4)$ \\
\hline $\mathrm{Dr}_{\mathrm{ir}}$ & $\mathrm{DU} \sim(0,2)$ & $\mathrm{DU} \sim(0,5)$ & $\mathrm{DU} \sim(0,10)$ \\
\hline $\operatorname{Dr}_{\text {ir' }}^{\prime}$ & $\mathrm{DU} \sim(0,2)$ & $\mathrm{DU} \sim(0,5)$ & $\mathrm{DU} \sim(0,10)$ \\
\hline $\operatorname{Lag}_{\mathrm{i}, \mathrm{j}}$ & DU (0,1) & DU (0,1) & DU (0,2) \\
\hline $\mathrm{IR}_{\mathrm{r}}$ & $\mathrm{DU} \sim(2,7)$ & $\mathrm{DU} \sim(5,10)$ & $\mathrm{DU} \sim(10,20)$ \\
\hline $\mathrm{IR}_{\mathrm{r}}^{\prime}$ & $\mathrm{DU} \sim(2,7)$ & $\mathrm{DU} \sim(5,10)$ & $\mathrm{DU} \sim(10,20)$ \\
\hline $\mathrm{MR}_{\mathrm{r}}$ & $\mathrm{DU} \sim(2,12)$ & $\mathrm{DU} \sim(5,25)$ & $\mathrm{DU} \sim(10,50)$ \\
\hline $\mathrm{MR}_{\mathrm{r}}^{\prime}$ & $\mathrm{DU} \sim(2,12)$ & $\mathrm{DU} \sim(5,25)$ & $\mathrm{DU} \sim(10,50)$ \\
\hline $\mathrm{RC}_{\mathrm{s}}$ & $\mathrm{U}^{*} \sim(2000,2500)$ & $\mathrm{U} \sim(2200,2700)$ & $\mathrm{U} \sim(2400,2900)$ \\
\hline $\mathrm{HC}_{\mathrm{r}}^{\prime}$ & $\mathrm{U} \sim(1100,1400)$ & $\mathrm{U} \sim(1100,1400)$ & $\mathrm{U} \sim(1100,1400)$ \\
\hline $\mathrm{NC}_{\mathrm{r}}$ & $\mathrm{U} \sim(120,1400)$ & $\mathrm{U} \sim(120,1400)$ & $\mathrm{U} \sim(120,1400)$ \\
\hline $\mathrm{PC}_{\mathrm{i}}$ & $\mathrm{U} \sim(250,350)$ & $\mathrm{U} \sim(250,350)$ & $\mathrm{U} \sim(250,350)$ \\
\hline $\mathrm{InCap}_{\mathrm{u}}$ & $\mathrm{U} \sim(0,30)$ & $\mathrm{U} \sim(0,60)$ & $\mathrm{U} \sim(0,120)$ \\
\hline OutCap $_{u}$ & $\mathrm{U} \sim(1,25)$ & $\mathrm{U} \sim(2,50)$ & $\mathrm{U} \sim(4,100)$ \\
\hline $\mathrm{FCap}_{\mathrm{u}}$ & $\mathrm{U} \sim(5,50)$ & $\mathrm{U} \sim(10,100)$ & $\mathrm{U} \sim(20,200)$ \\
\hline $\mathrm{IMC}_{\operatorname{lnm}(\operatorname{lm}, \mathrm{m}), \mathrm{t}}$ & $\mathrm{U} \sim(1,25)$ & $\mathrm{U} \sim(2,60)$ & $\mathrm{U} \sim(4,100)$ \\
\hline $\mathrm{IRC}_{\operatorname{lnr}(\mathrm{lr}, \mathrm{c}), \mathrm{t}}$ & $\mathrm{U} \sim(1,25)$ & $\mathrm{U} \sim(2,60)$ & $\mathrm{U} \sim(4,100)$ \\
\hline
\end{tabular}




\begin{tabular}{|c|c|c|c|}
\hline $\mathrm{WM}_{\mathrm{pm}, \mathrm{lm}}:$ & $\mathrm{U} \sim(1,2)$ & $\mathrm{U} \sim(1,2)$ & $\mathrm{U} \sim(1,2)$ \\
\hline $\mathrm{WR}_{\mathrm{w}, \mathrm{lr}}$ : & $\mathrm{U} \sim(1,2)$ & $\mathrm{U} \sim(1,2)$ & $\mathrm{U} \sim(1,2)$ \\
\hline $\mathrm{TC}_{\mathrm{f}(\mathrm{o}, \mathrm{d}, \mathrm{p})}$ & $\mathrm{U} \sim(10,20)$ & $\mathrm{U} \sim(10,20)$ & $\mathrm{U} \sim(10,20)$ \\
\hline $\mathrm{TL}_{\mathrm{f}(\mathrm{o}, \mathrm{d}, \mathrm{p})}$ & $\mathrm{U} \sim(0,2)$ & $\mathrm{U} \sim(0,2)$ & $\mathrm{U} \sim(0,2)$ \\
\hline $\operatorname{PrL}_{\mathrm{im}}(\mathrm{lm}, \mathrm{m}, \mathrm{pm})$ & $\mathrm{U} \sim(0,1)$ & $\mathrm{U} \sim(0,1)$ & $\mathrm{U} \sim(0,1)$ \\
\hline $\mathrm{SC}_{\mathrm{p}}$ & $\mathrm{U} \sim(0.2,20)$ & $\mathrm{U} \sim(0.2,20)$ & $\mathrm{U} \sim(0.2,20)$ \\
\hline$C f_{p}$ & $\mathrm{U} \sim(1,2)$ & $\mathrm{U} \sim(1,2)$ & $\mathrm{U} \sim(1,2)$ \\
\hline $\mathrm{PRC}_{\mathrm{pm}}$ & $\mathrm{U} \sim(50,300)$ & $\mathrm{U} \sim(50,300)$ & $\mathrm{U} \sim(50,300)$ \\
\hline $\mathrm{RRC}_{\mathrm{w}}$ & $\mathrm{U} \sim(1,50)$ & $\mathrm{U} \sim(1,50)$ & $\mathrm{U} \sim(1,50)$ \\
\hline $\mathrm{AP}_{\operatorname{lnm}(\operatorname{lm}, \mathrm{m})}$ & $\mathrm{U} \sim(90,300)$ & $\mathrm{U} \sim(90,300)$ & $\mathrm{U} \sim(90,300)$ \\
\hline $\mathrm{AR}_{\mathrm{lnr}(\mathrm{lr}, \mathrm{c})}$ & $\mathrm{U} \sim(60,120)$ & $\mathrm{U} \sim(60,1200)$ & $\mathrm{U} \sim(60,120)$ \\
\hline $\mathrm{Q}_{\left(\mathrm{p}_{1}, \mathrm{p}_{2}\right)}$ & $\mathrm{U} \sim(1,5)$ & $\mathrm{U} \sim(1,5)$ & $\mathrm{U} \sim(1,5)$ \\
\hline $\mathrm{WP}_{\mathrm{w}, \mathrm{i}}$ & $\mathrm{U} \sim(0,2.8)$ & $\mathrm{U} \sim(0,2.8)$ & $\mathrm{U} \sim(0,2.8)$ \\
\hline $\mathrm{D}_{\mathrm{i}}$ & $\mathrm{DU} \sim(0,2)$ & $\mathrm{DU} \sim(0,2)$ & $\mathrm{DU} \sim(0,3)$ \\
\hline $\mathrm{ET}_{\mathrm{i}}$ & $\mathrm{DU} \sim(7,24)$ & $\mathrm{DU} \sim(7,24)$ & $\mathrm{DU} \sim(7,24)$ \\
\hline $\mathrm{LT}_{\mathrm{i}}$ & $\mathrm{DU} \sim(7,31)$ & $\mathrm{DU} \sim(7,31)$ & $\mathrm{DU} \sim(7,31)$ \\
\hline $\mathrm{RC}_{\mathrm{s}}$ & $\mathrm{U} \sim(2500,2700)$ & $\mathrm{U} \sim(2500,3000)$ & $\mathrm{U} \sim(2500,3500)$ \\
\hline $\mathrm{HC}_{\mathrm{r}}$ & $\mathrm{U} \sim(1200,1500)$ & $\mathrm{U} \sim(1200,1500)$ & $\mathrm{U} \sim(1200,1500)$ \\
\hline $\mathrm{NC}_{\mathrm{r}}$ & $\mathrm{U} \sim(100,300)$ & $\mathrm{U} \sim(100,300)$ & $\mathrm{U} \sim(100,300)$ \\
\hline $\mathrm{PC}_{\mathrm{i}}$ & $\mathrm{U} \sim(200,500)$ & $\mathrm{U} \sim(200,500)$ & $\mathrm{U} \sim(200,500)$ \\
\hline $\mathrm{TC}_{\mathrm{f}(\mathrm{o}, \mathrm{d}, \mathrm{p})}$ & $\mathrm{U} \sim(10,150)$ & $\mathrm{U} \sim(10,150)$ & $\mathrm{U} \sim(10,150)$ \\
\hline $\mathrm{SC}_{\mathrm{p}}$ & $\mathrm{U} \sim(0,500)$ & $\mathrm{U} \sim(0,500)$ & $\mathrm{U} \sim(0,500)$ \\
\hline $\mathrm{PRC}_{\mathrm{pm}}$ & $\mathrm{U} \sim(100,1000)$ & $\mathrm{U} \sim(100,1000)$ & $\mathrm{U} \sim(100,1000)$ \\
\hline $\mathrm{RRC}_{\mathrm{w}}$ & $\mathrm{U} \sim(50,70)$ & $\mathrm{U} \sim(50,70)$ & $\mathrm{U} \sim(50,70)$ \\
\hline $\mathrm{AP}_{\operatorname{lnm}(\operatorname{lm}, \mathrm{m})}$ & $\mathrm{U} \sim(100,1000)$ & $\mathrm{U} \sim(100,1000)$ & $\mathrm{U} \sim(100,1000)$ \\
\hline $\mathrm{AR}_{\operatorname{lnr}(1 \mathrm{l}, \mathrm{c})}$ & $\mathrm{U} \sim(50,100)$ & $\mathrm{U} \sim(50,100)$ & $\mathrm{U} \sim(50,100)$ \\
\hline
\end{tabular}

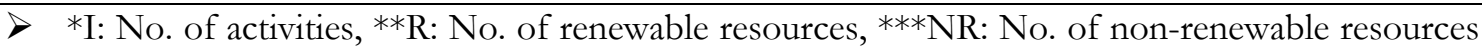
and ${ }^{* * * *} \mathrm{~T}$ : No. of time periods.

DU*: Discrete uniform distribution, $\mathrm{U}^{*}$ : Continuous uniform distribution.

$>\mathrm{We}$ note that $\mathrm{ET}_{\mathrm{i}}$ (earliest start time of activity i) and $\mathrm{LT}_{\mathrm{i}}$ (latest start time of activity i) are estimated according to the precedency relations in the activity on node diagram as well as the lag time that are exist between activities. In general, they take values as presented hereabove. 


\section{Declarations}

\section{Funding}

The study was financialy supported by the French Agency of Environment and Energy Management (in French: Agence de l'Environnement et de la Maîtrise de l'Énergie) through grant number $1282 \mathrm{C} 0305$.

\section{Conflicts of interest/Competing interests}

On behalf of all authors, the corresponding author states that there is no conflict of interest.

\section{Availability of data and material}

Not applicable.

\section{Code availability}

Not applicable.

\section{References}

Aquilano NJ, Smith DE (1980) A formal set of algorithms for project scheduling with critical path scheduling/material requirements planning. J Oper Manag 1(2):57-67.

Ahuja HN. 1976. Construction Performance Control by Networks. [place unknown]: Wiley.

Alcaraz J, Maroto C (2001) A Robust Genetic Algorithm for Resource Allocation in Project Scheduling. Ann Oper Res 102(1):83-109.

Bandyopadhyay, S., Foo, D. C. Y., \&Tan, R. R. (2017). Pursuing Sustainability with Process Integration and Optimization. Process Integr Optim Sustain 1(1), 1-2.

Battini D, Bogataj M, Choudhary A (2017) Closed Loop Supply Chain (CLSC): Economics, Modelling, Management and Control. Int J Prod Econ 183:319-321.

Blazewicz J, Lenstra JK, Kan AHGR (1983) Scheduling subject to resource constraints: classification and complexity. Discrete Appl Math 5(1):11-24.

Browning TR, Yassine AA (2010) Resource-constrained multi-project scheduling: Priority rule performance revisited. Int J Prod Econ 126(2):212-228.

de Kok TG, Fransoo JC (2003) Planning Supply Chain Operations: Definition and Comparison of Planning Concepts. In: Handbooks in Operations Research and Management Science [Internet]. Vol. 
11. [place unknown]: Elsevier; [accessed 2020 Apr 6]; p. 597-675.

Dodin B, Elimam AA (2001) Integrated Project Scheduling and Material Planning with Variable Activity Duration and Rewards. IIE Transactions 33(11):1005-1018.

Gálvez-Martos J-L, Styles D, Schoenberger H, Zeschmar-Lahl B (2018) Construction and demolition waste best management practice in Europe. Resources, Conservation and Recycling 136:166-178.

Gholizadeh-Tayyar, S, Lamothe, J, Dupont, L, Loustau, J.-P. (2018) A Decisional Framework for Concurrent Planning of Multiple Projects and Supply Chain Network. Inf Syst, Logistics, and Supply Chain 122-107. Springer International Publishing.

Gonçalves JF, Mendes JJM, Resende MGC (2008) A genetic algorithm for the resource constrained multi-project scheduling problem. Eur J Oper Res 189(3):1171-1190.

Habibi F, Barzinpour F, Sadjadi SJ (2019) A mathematical model for project scheduling and material ordering problem with sustainability considerations: A case study in Iran. Comput Ind Eng 128:690710.

Herroelen W (2005) Project Scheduling—Theory and Practice. Prod Oper Manag 14(4):413-432.

Holland, J.H (1976) Adaption in natural and artificial systems. University of Michigan Press.

Jain, S., Gupta, S., Thomas, N., \& Bandyopadhyay, S. (2020). Capacity Expansion of Electricity Sector Using Multiple Sustainability Indicators. Process Integr Optim Sustain 4(1), 51-65.

Kannan G, Sasikumar P, Devika K (2010) A genetic algorithm approach for solving a closed loop supply chain model: A case of battery recycling. Appl Math Model 34(3):655-670.

KELLEY JE (1963) The Critical-Path Method: Resource Planning and Scheduling. Industrial Scheduling [Internet]. [accessed 2020 Apr 6].

Kim J, Chung BD, Kang Y, Jeong B (2018) Robust optimization model for closed-loop supply chain planning under reverse logistics flow and demand uncertainty. J Cleaner Prod 196:1314-1328.

Lachimpadi SK, Pereira JJ, Taha MR, Mokhtar M (2012) Construction waste minimisation comparing conventional and precast construction (Mixed System and IBS) methods in high-rise buildings: A Malaysia case study. Resources, Conservation and Recycling 68:96-103.

Légifrance (2009) Arrêté du 29 septembre 2009 relatif au contenu et aux conditions d'attribution du label « haute performance énergétique rénovation ». 29 septembre 2009. 
Lova A, Tormos P (2001) Analysis of Scheduling Schemes and Heuristic Rules Performance in Resource-Constrained Multi project Scheduling. Ann Oper Res 102(1):263-286.

Niaki STA, Najafi AA, Zoraghi N, Abbasi B (2015) Resource Constrained Project Scheduling with Material Ordering: Two Hybridized Meta-Heuristic Approaches (TECHNICAL NOTE). Int J Eng 28(6):896-902.

Nima Z, Abbas NA, Taghi ANS. 2012. AN INTEGRATED MODEL OF PROJECT SCHEDULING AND MATERIAL ORDERING: A HYBRID SIMULATED ANNEALING AND GENETIC ALGORITHM. 6(110):19-27.

Pritsker AAB, Watters LJ, Wolfe PM (1969) Multi project Scheduling with Limited Resources: A Zero-One Programming Approach. Mana Sci 16(1):93-108.

Prakash, S., Kumar, S., Soni, G., Jain, V., \& Rathore, A. P. S. (2020). Closed-loop supply chain network design and modelling under risks and demand uncertainty: An integrated robust optimization approach. Ann Oper Res, 290(1), 837-864.

Rabbani, M., Ahmadzadeh, K., \&Farrokhi-Asl, H. (2019). Remanufacturing Models Under Technology Licensing with Consideration of Environmental Issues. Process Integr Optim Sustain 3(3), 383-401.

Robichaud Lauren Bradley, Anantatmula Vittal S (2011) Greening Project Management Practices for Sustainable Construction. J Manag Eng 27(1):48-57.

Sheikh Sajadieh M., Shadrokh, S., Hassanzadeh F (2009) CONCURRENT PROJECT SCHEDULING AND MATERIAL PLANNING: A GENETIC ALGORITHM APPROACH. 16(2):91-99.

Shen LY, Tam VWY (2002) Implementation of environmental management in the Hong Kong construction industry. Int J Proj Manag 20(7):535-543.

Smith-Daniels DE, Aquilano NJ (1984) Constrained resource project scheduling subject to material constraints. J OperManag 4(4):369-387.

Smith-Daniels DE, Smith-Daniels VL (1987a) Maximizing the net present value of a project subject to materials and capital constraints. J Oper Manag 7(1):33-45.

Smith-Daniels DE, Smith-Daniels VL (1987b) Optimal Project Scheduling with Materials Ordering. IIE Transactions 19(2):122-129. 
Subramanian P, Ramkumar N, Narendran TT, Ganesh K (2012)A technical note on 'Analysis of closed loop supply chain using genetic algorithm and particle swarm optimisation.' Int J Prod Res 50(2):593-602.

Tabrizi BH, Ghaderi SF (2015) An Integrated Mixed-Integer Programming Model to Address Concurrent Project Scheduling and Material Ordering. Int J Industrial Manufacturing Eng 9(11):4.

Tabrizi BH, Ghaderi SF (2016) A robust bi-objective model for concurrent planning of project scheduling and material procurement. Comput Ind Eng 98:11-29.

Taguchi G, Organization AP (1986) Introduction to quality engineering: designing quality into products and processes. [place unknown]: The Organization.

Tayyar SG, Roy D, Ghaderi SF (2013) Economic, environmental and social responsible supply chain design using differential evolution multi objective algorithm. IEEE International Conference on In Eng Eng Manag pp 1617-1621.

Torabzadeh Khorasani, S. (2018). Green Supplier Evaluation by Using the Integrated Fuzzy AHP Model and Fuzzy Copras. Process Integr Optim Sustain 2(1), 17-25.

Toklu YC. 2002. Application of genetic algorithms to construction scheduling with or without resource constraints. Can J Civ Eng 29(3):421-429.

Tseng L-Y, Liang S-C (2006) A Hybrid Metaheuristic for the Quadratic Assignment Problem. Comput Optim Applic 34(1):85-113.

Udawatta N, Zuo J, Chiveralls K, Zillante G (2015) Improving waste management in construction projects: An Australian study. Resources, Conservation and Recycling 101:73-83.

Vallada E, Ruiz R (2011) A genetic algorithm for the unrelated parallel machine scheduling problem with sequence dependent setup times. Eur J Oper Res 211(3):612-622.

Wang J, Wu H, Duan H, Zillante G, Zuo J, Yuan H (2018) Combining life cycle assessment and Building Information Modelling to account for carbon emission of building demolition waste: A case study. J Cleaner Prod 172:3154-3166.

Wauters T, Kinable J, Smet P, Vancroonenburg W, Vanden Berghe G, Verstichel J (2016) The Multi-Mode Resource-Constrained Multi-Project Scheduling Problem. J Sched 19(3):271-283.

Węglarz J, Józefowska J, Mika M, Waligóra G (2011) Project scheduling with finite or infinite number of activity processing modes - A survey. Eur J Oper Res 208(3):177-205. 
Zamani R (2019) An effective mirror-based genetic algorithm for scheduling multi-mode resource constrained projects. Comput Ind Eng 127:914-924.

Zoraghi N, Shahsavar A, Niaki STA (2017) A hybrid project scheduling and material ordering problem: Modeling and solution algorithms. Appl Soft Computing. 58:700-713. 